\title{
El derecho al agua en el Perú y la critica al antropocentrismo jurídico desde el Nuevo Constitucionalismo Latinoamericano*
}

\section{The Right to Water in Peru and the Criticism of the Legal Anthropocentrism from the New Latin American Constitutionalism}

Ilda Nadia Mónica de la Asunción Pari Bedoya** https://orcid.org/0000-0002-2078-3175 http://dx.doi.org/10.21503/lex.v18i26.2175

* El presente artículo deriva de la tesis para optar el título de abogada denominada "El Derecho al Agua en el Perú desde el Nuevo Constitucionalismo Latinoamericano", presentada en la Universidad Privada de Tacna en diciembre de 2019.

** Maestranda en Filosofía con mención en Ética y Filosofía Política de la Universidad Nacional de San Agustín de Arequipa. Estudios concluidos del Máster en Cuestiones Contemporáneas en Derechos Humanos de la Universidad Pablo de Olavide, España. Abogada por la Universidad Privada de Tacna. Consultora e investigadora en Instituto Diálogos. Tacna-Perú.

Correo electrónico: iparib@unsa.edu.pe
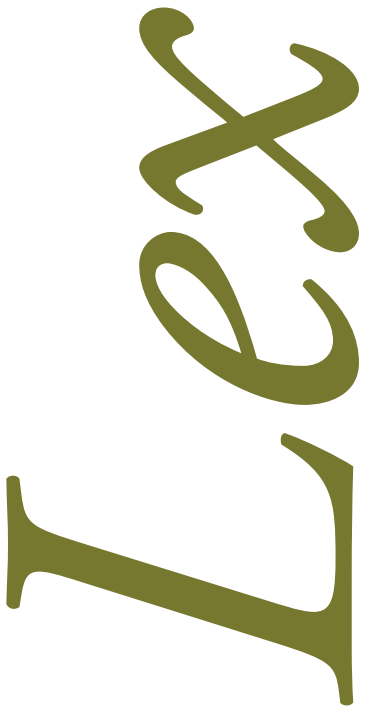


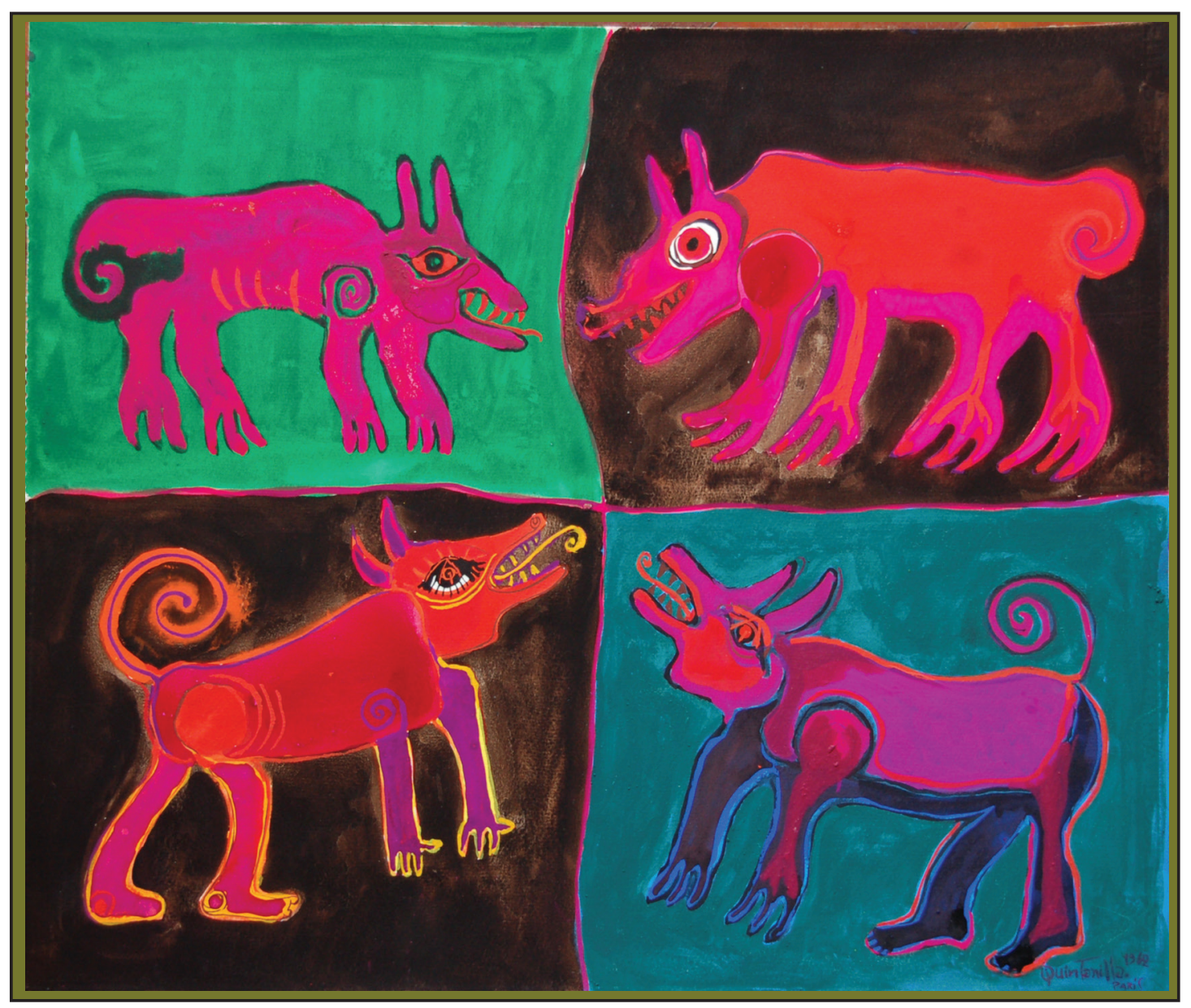

Filigrana entre perros. Óleo, 1962. Artista plástico peruano, Alberto Quintanilla (Cusco, 1934). 


\section{RESUMEN}

El giro que supuso la incorporación de sectores postergados históricamente como los pueblos indígenas en los procesos constituyentes de Bolivia y Ecuador, ha dado como resultado la consagración de nuevos principios como base del Nuevo Constitucionalismo Latinoamericano, el "Buen Vivir", inspirado en las cosmovisiones andinas. Las ideas del Buen Vivir suponen la deconstrucción de la manera en la que se concibe la relación los seres humanos y la naturaleza (una ruptura epistemológica que pone en cuestión las concepciones de sujeto y objeto de la razón instrumental occidental). Es así, que dada nuestra condición como país pluricultural, conviene analizar la consagración del derecho al agua en el Perú, tan importante en un espacio donde coexisten diversas concepciones sobre la vida, el desarrollo, la relación entre los seres humanos y la naturaleza, etc., bajo categorías que permitan incorporar las voces de aquellos sectores subalternos que terminan siendo los más afectados frente a la incomprensión de las instituciones jurídico-políticas, situación que muchas veces no puede ser percibida desde las teorías hegemónicas.

Palabras clave: agua, constitucionalismo, pueblos indígenas.

\section{ABSTRACT}

The turn involved in the incorporation of historically neglected sectors such as indigenous peoples in the constituent processes of Bolivia and Ecuador, has resulted in the consecration of new principles as the basis of the New Latin American Constitutionalism, the "Good Living", inspired by the Andean worldviews. The ideas of Good Living suppose the deconstruction of the way in which the relationship between human beings and nature is conceived (an epistemological break that calls into question the conceptions of subject and object of Western instrumental reason). Thus, given our condition as a multicultural country, it is convenient to analyze the consecration of the right to water in Peru, so important in a space where different conceptions of life, development, the relationship between human beings and nature, etc. ., under categories that allow incorporating the voices of those subaltern sectors that end up being the most affected in the face of the misunderstanding of legal-political institutions, a situation that often cannot be perceived from hegemonic theories

Key words: water, constitutionalism, indigenous people. 


\section{INTRODUCCIÓN}

El agua representa alrededor del 60\% del peso corporal del ser humano y es invariablemente su principal constituyente, por lo que es imprescindible para su vida. Siendo necesaria no solo para su subsistencia sino para el desarrollo de su vida diaria, según la Organización Mundial de la Salud (en adelante OMS), 50 a 100 litros de agua son requeridos por persona diariamente para cubrir sus necesidades básicas y evadir problemas de salud ${ }^{1}$. Al primer semestre del año 2016, se estima que la población peruana asciende a 31 millones donde solo el $67,1 \%$ de personas tenían acceso al agua potable"2 .

En el año 1977 en Mar de Plata (Argentina) se llevó a cabo la Conferencia de las Naciones Unidas sobre el Agua, donde se habla sobre la cantidad de agua mínima admisible para la satisfacción de necesidades básicas, siendo tratado por primera vez el tema en torno a la cantidad necesaria de agua a la cual debe tener acceso el ser humano no solo para poder sobrevivir (consumo) sino para poder desarrollarse, señalando que "todos los pueblos, cualesquiera que sean su etapa de desarrollo y sus condiciones económicas y sociales, tienen derecho al agua potable en cantidad y calidad acordes con sus necesidades básicas"3 . Posteriormente, varios otros planes de acción han mencionado el agua potable y el saneamiento como un derecho humano.

Aunado a ello, se cuenta con la Observación General No 15 del Comité de Derechos Económicos, Sociales y Culturales de las Naciones Unidas (Comité DESC), desarrollando no solo el tema de la cantidad de agua mínima que debe disponer el ser humano sino que pasa a establecer características del agua destinada para consumo humano, estipulando que, "el derecho humano al agua es el derecho de todos de disponer de agua suficiente, salubre, aceptable, accesible y asequible para uso personal y doméstico" ${ }^{4}$. Del mismo modo, la Asamblea General de las Naciones Unidas en julio de 2010 reconoce

1. Organización Mundial de la Salud, "El Derecho al agua", folleto Informativo N 35, 2011, p. 9, acceso el 25 de noviembre de 2019, https://www.ohchr.org/Documents/Publications/FactSheet35sp.pdf

2. Instituto Nacional de Estadística e Informática, "Perú: Formas de acceso al agua y Saneamiento Básico - Síntesis Estadística”, 2016, 5, acceso el 05 de diciembre de 2019, https://www.inei.gob.pe/media/MenuRecursivo/boletines/ boletin_agua.pdf

3. Organización Mundial de la Salud, óp. cit., 9. https://www.ohchr.org/Documents/Publications/FactSheet35sp.pdf

4. Comité de Derechos Económicos, Sociales y Culturales. Observación General No 15: El derecho al agua (artículos 11 y 12 del Pacto Internacional de Derechos Económicos, Sociales y Culturales). E/C.12/2002/11. 20 de enero de 2003. 
el derecho humano al agua como un derecho autónomo 5 . Sin embargo, al observar el Sistema Interamericano se puede apreciar que no se presenta definición para del derecho al agua. Por otro lado, en el Protocolo de San Salvador si bien no se refiere al derecho al agua de manera directa, se puede encontrar a través de la interpretación de su artículo 11.1 (derecho a un medio ambiente sano), donde se reconoce a toda persona el derecho de contar con los servicios básicos.

Con fecha 22 de junio del 2017 se publica en el diario oficial El Peruano la Ley de Reforma Constitucional - Ley 30 588, la cual incorpora el artículo 7º-A en la Constitución Política del Estado la cual establece "El Estado reconoce el derecho de toda persona a acceder de forma progresiva y universal al agua potable. El Estado garantiza este derecho priorizando el consumo humano sobre otros usos. El Estado promueve el manejo sostenible del agua, el cual se reconoce como un recurso natural esencial y como tal, constituye un bien público y patrimonio de la Nación. Su dominio es inalienable e imprescriptible".

De esta manera su reconocimiento expreso en la constitución implica que "los ciudadanos tienen una pretensión justificada que les permite exigir las correlativas obligaciones por parte del Estado"6 , sin embargo, su reciente incorporación a nuestro ordenamiento jurídico implica un escaso desarrollo a nivel legislativo, jurisprudencial y doctrinal que permita identificar con claridad el contenido constitucionalmente protegido de dicho derecho, entendido en primer lugar como aquella sujeta a tutela ${ }^{7}$ directa, inmediata y presta de un derecho fundamental y en segundo lugar como aquello que ya no es susceptible de tutela . Ejemplo de esto es que en el artículo 5.1 del Código Procesal Constitucional ha dispuesto que "no proceden los procesos constitucionales cuando (...) los hechos y el petitorio de la demanda no están referidos en forma directa al contenido constitucionalmente protegido del derecho invocado"; por lo que al no existir certeza de su contenido, puede llevar a que la ciudadanía este desprotegida ante una posible vulneración de derechos, ya que los jueces para poder resolver con claridad los casos que invoquen el derecho al agua potable, deben tener presente sus límites y su aplicación en el ordenamiento jurídico peruano, lo que exige realizar una interpretación sistemática en tanto es posible comprender al derecho al agua potable como un derivado del Derecho al Agua como derecho humano.

Sin embargo, la configuración de este derecho no puede analizarse de manera aislada, toda vez que en los últimos ańos se han producido cambios importantes en el constitucionalismo latinoamericano en materia de derechos ambientales o "derechos de la naturaleza". Estos cambios que han puesto en

5. Organización de las Naciones Unidas, Resolución de la Asamblea General A/64/L.63/Rev.1. 26 de julio de 2010.

6. C. Soriano, Y. Jacobo y J. Núñez, "El Reconocimiento Constitucional del Derecho al Agua en el Salvador" (tesis de grado, Universidad de El Salvador, 2012), 13.

7. Edwin Figueroa, "Contenido Constitucionalmente Protegido de un Derecho Fundamental: Reglas para su Determinación”, 2014, 4, acceso el 05 de diciembre de 2019,

https://edwinfigueroag.wordpress.com/2014/04/16/derechos-fundamentales-el-contenido-constitucionalmenteprotegido-articulo/ 
cuestión las principales instituciones heredadas del constitucionalismo europeo y sus presupuestos filosóficos que han sido la base del devenir económico, político y social en esta parte del mundo desde finales del siglo XVII, han sido interpretados como un nuevo modelo de constitucionalismo: el "Nuevo Constitucionalismo Latinoamericano". Esta corriente, ha permitido develar las falencias de las teorías hegemónicas del derecho en América Latina para responder a una realidad bastante compleja caracterizada principalmente por la pluriculturalidad ${ }^{8}$.

El giro que supuso la incorporación de sectores postergados históricamente como los pueblos indígenas en los procesos constituyentes de Bolivia y Ecuador, ha dado como resultado la consagración de nuevos principios como base de este modelo de constitucionalismo, el "Buen Vivir", inspirado en las cosmovisiones andinas. Las ideas del Buen Vivir suponen la deconstrucción de la manera en la que se concibe la relación los seres humanos y la naturaleza (una ruptura epistemológica que pone en cuestión las concepciones de sujeto y objeto de la razón instrumental occidental). Es así, que dada nuestra condición como país pluricultural, conviene analizar la consagración de este derecho tan importante en un espacio donde coexisten diversas concepciones sobre la vida, el desarrollo, la relación entre los seres humanos y la naturaleza, etc., bajo categorías que permitan incorporar las voces de aquellos sectores subalternos que terminan siendo los más afectados frente a la incomprensión de las instituciones jurídico-políticas, situación que muchas veces no puede ser percibida desde las teorías hegemónicas.

\section{NUEVO CONSTITUCIONALISMO LATINOAMERICANO}

Preliminarmente, conviene diferenciar entre la constitución formal (la aprobación de los textos constitucionales ${ }^{9}$ y el material (situación o situaciones por las cuales se acepta el cambio de Constitución) ${ }^{10}$. En el caso del Nuevo Constitucionalismo latinoamericano, podemos observar que producto de la lucha de fuerzas sociales, es que se incorporan nuevos sujetos (como los pueblos indígenas) ${ }^{11}$. En los procesos constituyentes que dieron origen a las cartas fundamentales de Bolivia (2009) y Ecuador (2008), la Constitución volvió a ser obra de su titular originario: el poder constituyente, es decir, el pueblo $^{12}$. Esto se explica, en tanto el poder constituyente es la expresión de la voluntad política cuya

8. Por ejemplo, el caso de la oposición del líder indígena de los Harakmbut en Madre de Dios a la construcción de carreteras y la minería en la región, quien apelaba a las rocas, en especial al "Rostro de Haramkbut" para protección. Fernando Gilmeno, "El rostro Harakmbut, redescubierto como arma indígena ante la deforestación”. La Información, 26 de feb. de 2016, acceso el 05 de diciembre de 2019, https://www.lainformacion.com/economia-negocios-y-finanzas/ el-rostro-harakmbut-redescubierto-como-arma-indigena-ante-la-deforestacion_qcsO5Te2eXHjMzoMmSw6X1/

9. Si bien se considera como parte del Nuevo Constitucionalismo Latinoamericano a la Constitución vigente de Venezuela, para el presente trabajo nos enfocaremos en las constituciones de Ecuador y Bolivia en tanto para nuestro objeto de estudio, en tanto en encontramos un alto nivel de importancia y de desarrollo de los principios del Buen Vivir y los derechos de la naturaleza.

10. Aurora Molina, "Nuevo constitucionalismo en América Latina. Contexto sociopolítico, derechos sociales. Entrevista a Carlos Rivera Lugo", Crítica Jurídica, 35 (2013): 315-330, pp. 316-319.

11. Ilda Pari-Bedoya, "Notas sobre el 'buen vivir' y el 'Nuevo Constitucionalismo Latinoamericano' ", Pacarina del Sur, 38, año 10 (2019), acceso el 05 de diciembre de 2019,

www.pacarinadelsur.com/index.php?option=com_content\&view=article\&id=1703\&catid=3

12. Aurora Molina, "Nuevo constitucionalismo en América Latina. Contexto sociopolítico, derechos sociales. Entrevista a Carlos Rivera Lugo", op. cit., p. 318. 
fuerza permite determinar el modo de existencia política, es decir, el poder de darse a sí mismo una Constitución y de reformarla o sustituirla ${ }^{13}$. En este sentido, en democracia, el pueblo es el que detenta el poder constituyente, por lo que al resultar este sujeto (el pueblo) tan diverso y complejo en entornos como el latinoamericano, cobra sentido que las constituciones boliviana y ecuatoriana adopten un enfoque multiétnico, intercultural y plurinacional.

Para Nuria Belloso Martín ${ }^{14}$, el contexto donde se produce estos cambios, tiene como antecedentes dos periodos diferenciados respecto a la participación de los pueblos indígenas y el reconocimiento de sus derechos: 1) el primero se ubica entre 1982 y 1988, donde se inserta la idea de "diversidad cultural" para reconocer la composición multicultural de las sociedades latinoamericanas, se incorporan derechos para las poblaciones indígenas en las constituciones que surgen en ese periodo, sobre todo aquellas relativas a la posesión de tierras y el respeto a su identidad cultural; 2) el segundo se ubica entre los años 1989 al 2005, donde los derechos de los pueblos indígenas se internacionalizan a través del Convenio 169 de la OIT, se adopta el Estado constitucional, social y democrático de derecho como paradigma, lo que lleva a expandir los derechos fundamentales e incorporar mecanismos que garanticen la participación de los ciudadanos.

De esta manera, se presenta un modelo de Estado acorde a las exigencias de un estado constitucional, en tanto reconoce los derechos fundamentales y sus garantías, pero se extiende hacia la construcción de un estado democrático, social y plurinacional ${ }^{15}$. En este sentido, Martínez Dalmau señala que este modelo de constitucionalismo ha surgido como respuesta a la "demandas históricas del pueblo latinoamericano", por lo que entre sus objetivos se encuentra la inclusión de aquellas grandes mayorías que se han visto excluidas de los procesos de toma de decisiones ${ }^{16}$.

El Nuevo Constitucionalismo Latinoamericano presenta las siguientes características: 1) procesos constituyentes populares con participación de los movimientos sociales, 2) una alta presencia de principios y valores que sostienen la arquitectura constitucional y estatal, 3) nuevos modelos de Estado. 4) incorporación de nuevos derechos derivados de las demandas de los movimientos sociales, 5) incorporación de los valores indígenas en la Constitución y reconocimiento del pluralismo cultural y jurídico multinivel ${ }^{17}$.

Por lo que, podemos señalar que si bien el Nuevo Constitucionalismo Latinoamericano, surge como un modelo alternativo al modelo hegemónico neo-constitucional, no implica que deje de lado

13- Lautaro Ríos, “La Soberanía, el Poder Constituyente y una nueva constitución para Chile”, Estudios Constitucionales, 2, año 15 (2017): 167- 202, p. 183.

14. Nuria Belloso, "El Neoconstitucionalismo y el 'Nuevo' Constitucionalismo Latinoamericano: ¿Dos corrientes llamadas a entenderse?”, Cuadernos Electrónicos de Filosofía del Derecho, 32 (2015): 21-53, p. 26.

15. Ilda Pari-Bedoya, "Notas sobre el 'buen vivir' y el 'Nuevo Constitucionalismo Latinoamericano' ", op. cit., acceso el 05 de diciembre de 2019,

www.pacarinadelsur.com/index.php?option=com_content\&view=article\&id=1703\&catid=3

16. Aquiles Sotillo, "La nueva clasificación de los derechos fundamentales en el nuevo constitucionalismo latinoamericano". Revista Ciencia y Cultura, 35, vol. 19 (2015): 163-183, pp. 173-174.

17. Alejandro Rosillo, "Pluralismo Jurídico en el constitucionalismo mexicano frente al nuevo Constitucionalismo Latinoamericano". Revista Direito e Práxis, 4, vol.8 (2017):3037-3068, p. 3040. 
las dimensiones que permiten caracterizar a un Estado como un Estado Constitucional de Derecho: el respeto y la garantía de los derechos humanos, y la democracia como forma de gobierno. Sin, embargo, su carácter alternativo recae en la incorporación de instituciones provenientes de los pueblos originarios de América Latina, la creación de nuevos derechos y fundamentalmente una nueva relación entre el hombre y la naturaleza ${ }^{18}$.

\section{BUEN VIVIR}

El "Buen Vivir", "Sumak Kawsay" o "Suma Qamaña” es un conjunto de ideas que se originaron como un modelo alternativo de desarrollo basado en los aportes de diversas cosmovisiones ancestrales, las cuales han visto un resurgimiento en los últimos años al ser incorporadas en las constituciones de Bolivia y Ecuador ${ }^{19}$. Fernando Huanacuni Mamani, sostiene que este resurgimiento se debe a la combinación de recuperación de los saberes ancestrales con una política de soberanía nacional, promoviendo formas comunitarias de vida, la relación de los hombres con la Madre Tierra basada en la armonía y el equilibrio frente a la acumulación de capital ilimitada e individual ${ }^{20}$.

De esta manera, la finalidad de esta concepción alternativa de desarrollo es lograr la sustentabilidad a partir de generar una relación armoniosa entre el hombre y el medioambiente, considerando que no puede subordinarse a las naturalezas a las demandas arbitrarias del ser humanos. Para lograr estos fines, en el aspecto más radical de esta propuesta, se ha planteado el cambio de estatus jurídico de la naturaleza, de objeto a sujeto de derechos ${ }^{21}$. Dicha situación ha generado que surjan interrogantes, como aquella que se pregunta si estamos frente a derechos o declaraciones de propósitos, o si es posible que seres no humanos puedan ser sujetos de derechos. Éste último cuestionamiento, de ser respondido de manera afirmativa lleva a otras preguntas como la interrogante sobre el contenido de estos derechos, si estos debilitan la teoría de los derechos humanos o si son exigibles ${ }^{22}$.

$\mathrm{Al}$ respecto, podemos señalar que desde los 70, a partir del Informe del Club de Roma titulado "Limites del crecimiento" se habla de la crisis inminente ante el agotamiento de los recursos y el de-

18. José Manuel Velázquez, “Constitucionalismo verde en Ecuador: Derechos de la Madre Tierra y Buen Vivir". Entramado, 1, vol.10 (2014): 220-238, p. 223.

19. Ilda Pari-Bedoya, "Notas sobre el 'buen vivir' y el 'Nuevo Constitucionalismo Latinoamericano' ”, op. cit., acceso el 05 de diciembre de 2019,

www.pacarinadelsur.com/index.php?option=com_content\&view=article\&id=1703\&catid=3

20. Fernando Huanacuni, Buen Vivir / Vivir Bien: Filosofía, políticas, estrategias y experiencias regionales andinas, (Lima: Coordinadora Andina de Organizaciones Indígenas - CAOI, 2010), 22.

21. Ilda Pari-Bedoya, "Notas sobre el 'buen vivir' y el 'Nuevo Constitucionalismo Latinoamericano' ", op. cit., acceso el 05 de diciembre de 2019, www.pacarinadelsur.com/index.php?option=com_content\&view=article\&id=1703\&catid=3

22. Fernando Huanacuni, Buen Vivir / Vivir Bien: Filosofía, políticas, estrategias y experiencias regionales andinas, op. cit., 17. 
trimento del medioambiente ${ }^{23}$. Por lo que los cuestionamientos del carácter utópico de los derechos del buen vivir, es necesario advertir que hasta hace algunas décadas no podía hablarse de los derechos de algunos grupos minoritarios e incluso de la igualdad de género en los términos en los que hoy se debaten, por lo que ante la realidad alarmante propiciada por la manera en la que se ha construido la relación hombre-naturaleza desde la racionalidad occidental, han surgido propuestas alternativas como el Buen Vivir que han sido adoptadas por algunos Estados ${ }^{24}$.

\section{DERECHOS DE LA NATURALEZA}

Cambiar la concepción de naturaleza de bien jurídico a sujeto de derecho da pie a un debate filosófico en el plano ético, jurídico y político. Surgiendo preguntas como ¿¿Se devaluaría la dignidad humana? y ¿A quién le corresponde la titularidad de estos derechos? entre otras, sin embargo, esta propuesta surge como una opción ética que puede ser adoptada por los Estados para hacer frente a la sobreexplotación de recursos, contaminación ambiental y vulneración de los ecosistemas.

De esta manera, la "liberación de la naturaleza", que exige un esfuerzo político para pasar de ser un simple objeto de propiedad al reconocimiento como sujeto de derechos, lo que se traduciría en acabar con la identificación del bienestar como acumulación y crecimiento económico ilimitado ${ }^{25}$. Esto puede comprenderse mejor en el marco de la idea de desarrollo sostenible, la cual, según la Comisión Mundial sobre Medio Ambiente y Desarrollo de la ONU, implica que la satisfacción presente de las necesidades no puede comprometer la posibilidad de que las futuras generaciones puedan satisfacer las suyas $^{26}$. Por lo que, la incorporación de este nuevo modelo ético que plantea el Buen Vivir como una nueva forma de relacionarse entre los hombres y la naturaleza puede permitir materializar la idea de desarrollo sostenible, extendiéndola y situándola en el contexto latinoamericano.

Esta idea de la naturaleza como sujeto de derechos es producto de una visión ecocéntrica la cual consiste en "coloca[r] al ambiente y a la naturaleza como el eje central de las cuestiones ambientales. Esta corriente ha influenciado instrumentos tales como la Carta de la Naturaleza de la Naciones Unidas de 1982 en la cual se establece que la especie humana es parte de la naturaleza y la vida depende del funcionamiento ininterrumpido de los sistemas naturales"27. En yuxtaposición al antropocentrismo

23. Ignacio Rodríguez, "La tesis de los límites físicos del crecimiento: una revisión de los informes del Club de Roma", Perspectivas, 2, vol. 5 (2011): 75-103.

24. Ilda Pari-Bedoya, "Notas sobre el 'buen vivir' y el 'Nuevo Constitucionalismo Latinoamericano' ", op. cit., acceso el 05 de diciembre de 2019, www.pacarinadelsur.com/index.php?option=com_content\&view=article\&id=1703\&catid=3

25. Alberto Acosta, "Hacia la Declaración Universal de los Derechos de la Naturaleza Reflexiones para la acción", Revista de la Asociación de Funcionarios y Empleados del Servicio Exterior Ecuatoriano, 54 (2008): 18-20.

26. Gudynas Eduardo, Desarrollo, derechos de la naturaleza y buen vivir después de Montecristi, (Quito: Centro de Investigaciones Ciudad y Observatorio de la Cooperación al Desarrollo, 2011), 84.

27. René Bedón, “Contenido y aplicación de los derechos de la naturaleza”, IusHumani, vol. 5 (2016): 133-148, p. 135. 
dominante en la mayoría de países donde la naturaleza es vista como fuente de recursos que son puestos para la satisfacción de necesidades del ser humano, los derechos de la naturaleza y su concepción como sujeto de derecho, buscan tutelar la naturaleza, ello no significa que esté por encima del ser humano, sino que en base a principios como el de racionalidad el ser humano, la naturaleza y seres vivientes no son seres independientes entre sí, sino que comparten espacios donde han de relacionarse.

Para poder comprender ello deben observarse los principios de relacionalidad, correspondencia, el de complementariedad y el de reciprocidad. El primero concibe que no hay entes aislados; el segundo se refiere a la relación entre los diversos "campos" que componen la realidad, como son los campos simbólicos, ritualísticos, afectivos; el tercero se refiere a la coexistencia entre los entes o acciones con sus complementos específicos y la interdependencia entre ellos; y el último se refiere a que cada acción genera una acción en respuesta (la repercusión de los actos humanos y la idea de "justicia cósmica) ${ }^{28}$ . Es así como, el cambio de enfoque sobre la naturaleza supone el cambio de enfoque de la acción del ser humano en el mundo: la naturaleza tiene límites y no solo está como un proveedor de recursos, la naturaleza pasa a ser protegida ya no solamente porque supone un beneficio al ser humano.

\section{EL DERECHO AL AGUA EN EL NUEVO CONSTITUCIONALISMO LATINOAMERICANO}

El Nuevo Constitucionalismo Latinoamericano se opone o rivaliza contra el colonialismo, por un lado, para que el Estado pueda alcanzar una independencia respecto a otros Estados y por otro se puedan reconocer los derechos de grupos relegados como son las minorías culturales ante la indiferencia respecto a su participación en temas políticos, jurídicos y económicos. Estas constituciones buscan "cómo solucionar la desigualdad social"29 . Para dar cara a los problemas de naturaleza política y de participación el Nuevo Constitucionalismo latinoamericano hace uso de herramientas que propiciaran la inclusión social, la participación ciudadana e igualdad.

Estas herramientas pueden ser agrupadas en tres categorías: “(1) aquellas que operan en el proceso constituyente (previas a la Constitución), (2) aquellas de carácter normativo que se encuentran establecidas en el texto constitucional y, por último, (3) las que buscan hacer operativa la Carta Fundamental, por tanto, que operan durante la vigencia de la Constitución." ${ }^{30}$ En la búsqueda de la participación popular se establecen procesos participativos para que la ciudadanía pueda expresar su pluralidad, siendo multiculturalidad una característica de los países latinoamericanos. Como son la constitución de Bolivia y Ecuador.

28. Alberto Acosta y Esperanza Martínez, La Naturaleza con Derechos de la filosofía a la política, (Quito: Ediciones Abya-Yala, 2011), 216.

29. Hugo Tórtora, "Los derechos sociales en el nuevo constitucionalismo latinoamericano". Revista de Derechos Fundamentales, 13 (2015): 109-133, p. 113.

30. Ibídem. 
Viciano y Martínez, señala que este tipo de constituciones "tienen un "denominador común" que sería la "necesidad de legitimar la voluntad social de cambio mediante un intachable proceso constituyente de hechura democrática"."31 Hoy en día, no se puede negar que vivimos en un país pluricultural, por lo que el factor pluricultural debe ser tomada en cuenta al momento de que el Estado establezca las políticas públicas, debiendo implementarse o restructurase los canales democrático donde podrán participar activamente.

Por último, para Pedro Salazar Ugarte "las Constituciones del Nuevo Constitucionalismo Latinoamericano rompen políticamente con la tradición constitucional predominante en occidente y se distinguen por cuatro rasgos formales: su originalidad; su amplitud (tienen un articulado extenso); su complejidad (aunque tienen un lenguaje asequible y simbólico son técnicamente complejas); su pronunciada rigidez (para garantizar el predominio del poder constituyente soberano sobre los poderes constituidos)" 32 . En este sentido, su originalidad al incorporar nuevos conceptos como son el sumak kawsay y los derechos de la naturaleza (pachamama), si bien son significantes novedosos el significado con el que cargan es amplio encerrando toda una cosmovisión, siendo complejos no solo al interpretarlos sino también al aplicarlos, y la ciudadanía al participar en los procesos constituyentes y producto de ello impregnar los textos constitucionales se debe asegurar su esfuerzo a través de Constituciones rígidas.

\section{CONSTITUCIÓN DE ECUADOR}

Desde 1999 al 2007 se han producido el derrocamiento de tres gobiernos en Ecuador, debido a una institucionalidad política y administrativa deslegitimada por su incapacidad para garantizar las condiciones mínimas de vida y trabajo dignos (la credibilidad del congreso Nacional descendió hasta un $6 \%$ ), unos partidos políticos carenes de toda representatividad social, un sistema de justicia controlado por el poder político y económico (los procesos contra los banqueros causantes de la crisis se estancaron), entre otros aspectos representaron la ruptura del pacto social (...) hacia menos de tres décadas, ya habían dado como resultado una sociedad profundamente fracturada, que no se reconocía como un todo dinámico y orgánico en su rica diversidad ancestral y cultural políticamente desorientada.$^{33}$

Tras tomar posesión el 15 de enero de 2007, Rafael Correa, a través de un decreto convoca a la población para que participe en una consulta popular para decidir respecto a la factibilidad de realizarse una Asamblea (Decreto No. 2). Es así, que con fecha 15.04.2007 se llevó a cabo la Asamblea, arrojando

31. Pedro Salazar, "El Nuevo Constitucionalismo Latinoamericano (una perspectiva crítica)". En: El constitucionalismo contemporáneo. Homenaje a Jorge Carpizo, ed. L. González-Pérez y D. Valadés, 345-387, (México: Universidad Autónoma de México, 2013), 354.

32. Ibídem, p. 355.

33. Asamblea Nacional de la República de Ecuador, La Constitución de Montecristi, un sueño colectivo, el cambio hacia el buen vivir, (Quito: Asamblea Nacional de la republica de Ecuador), 16-17.

https://issuu.com/direccion.comunicacion/docs/memorias_asamblea_constituyente, pág. 16 
un resultado favorable a la Constituyente de $81,72 \%$. En su gran mayoría conforme indica el Carter Center "los asambleístas entrevistados por el Centro Carter (tanto de PAIS como de los bloques de minoría) coincidieron en señalar que el derecho al agua y los derechos de la naturaleza son aspectos centrales del nuevo proyecto de Constitución. Ambos derechos estarían dando un carácter pionero al nuevo texto respecto a otros marcos constitucionales." ${ }^{34}$ Al llevarse a cabo un proceso constituyente, la población entrevistada manifestó su deseo para que aspectos como el derecho al agua y la visión indígena del buen vivir sean plasmadas a nivel constitucional. Dado que este proceso constituyente tuvo como antecedentes, movimientos de gran envergadura por parte de la población entorno al recurso hídrico.

El inciso 1 del artículo $3^{\circ}$ de la Constitución de Ecuador establece que la garantía del derecho al agua es uno de los deberes primordiales del Estado. Siendo exigible por cuanto sirve de base para el desarrollo de los demás derechos. Pero estos derechos ha de interpretarse a la luz del "buen vivir", siendo que, en el numeral 5 del artículo $3^{\circ}$ se establece que dentro el Plan Nacional de Desarrollo de Ecuador se debe procurar "la erradicación de la pobreza, la promoción de un desarrollo sustentable y la redistribución equitativa de los recursos y la riqueza, para acceder al buen vivir”. Resaltando la cosmovisión de "buen vivir" bajo la cual se desarrolla comunidad ecuatoriana.

Sin embargo, como anotamos anteriormente, la particularidad de las Constituciones del Nuevo Constitucionalismo Latinoamericano no es plantear únicamente un modelo alternativo de desarrollo, sino que ha ido más allá reconociendo el estatus de sujeto de derechos a la naturaleza. De esta manera, en el artículo $10^{\circ}$ de la Constitución de Ecuador reconocen que los derechos consagrados en la Constitución recaen no solo a las personas (individuo) sino que también en las "comunidades, pueblos, nacionalidades y colectivos". Aunado a ello, es en el artículo $10^{\circ}$ donde se especifica el nuevo status de la naturaleza al señalar que "será sujeto de aquellos derechos que le reconozca la Constitución".

Entonces, podemos observar, que el artículo $10^{\circ}$ de la Constitución de Ecuador reconoce a la naturaleza como sujeto de derechos, pero solo de aquello derechos que se encuentra reconocidos a nivel constitucional. Por lo que pasare a mencionar los artículos donde se especifican los derechos que ostenta la naturaleza en Ecuador.

En el capítulo segundo se encuentran establecidos los derechos del "buen vivir", en la sección primera se encuentran los derechos relacionados al agua y la alimentación. El derecho al agua como derecho fundamental se encuentra regulado de manera precisa en el primer párrafo del artículo $12^{\circ}$, consagrándolo como un derecho irrenunciable, que conforma parte del patrimonio de la Nación "estratégico de uso público, inalienable, imprescriptible, inembargable y esencial para la vida”. No se puede prohibir que el ser humano haga uso del agua para su supervivencia y por ende no se puede prohibir que el

34. The Carter Center. Informe sobre la Asamblea Constituyente de la República del Ecuador, (Quito: Centro Carter, 2008), 5, acceso el 05 de diciembre de 2019,

https://www.cartercenter.org/resources/pdfs/peace/americas/Informe_Final_AC_-_Centro_Carter_distribuido.pdf 
Estado haga uso del agua para el bienestar de la Nación. Sin embargo, dicho uso debe encontrarse enmarcado dentro de los parámetros que plantea el "buen vivir".

La Constitución ecuatoriana, reconoce también el derecho a un ambiente ecológicamente equilibrado como garantía del buen vivir. Así en el artículo $14^{\circ}$ establece que este ambiente debe garantizar "la sostenibilidad y el buen vivir, sumak kawsay". Por lo que, el vivir en un ambiente sano y ecológicamente equilibrado pasa a ser de interés público, así señala el párrafo segundo del artículo $14^{\circ}$ : "Se declara de interés público la preservación del ambiente, la conservación de los ecosistemas, la biodiversidad y la integridad del patrimonio genético del país, la prevención del daño ambiental y la recuperación de los espacios naturales degradados".

En el artículo $15^{\circ}$ se establece que el Estado debe promoverá la sostenibilidad ambiental respecto al uso de tecnologías y que la búsqueda de soberanía energética no deberá afectar el derecho al agua. Por otro lado, en el artículo $32^{\circ}$ se vincula de manera explícita el derecho al agua con el derecho a la salud en tanto este último se encuentra íntimamente vinculado con los derechos del buen vivir.

Agustín Grijalva señala que "basado en relaciones interculturales igualitarias que redefinan y reinterpreten los derechos constitucionales y reestructuren la institucionalidad proveniente del Estado Nacional"35 el Estado ecuatoriano debe asegurar espacios de debate y deliberación democráticos sobre temas que afecten a las, comunas y pueblos indígenas, para asegurar la participación intercultural, basados en un principio de igualdad. Conforme se aprecia del articulo 57 incisos 6 y 7 . Es asi que el inciso 6 versa sobre la participación a través del "uso, usufructo, administración y conservación de los recursos naturales renovables que se hallen en sus tierras" siendo principal una participación de estas poblaciones por ser afectados directos. Asi también, el inciso 7 establece que para que el Estado haga uso de los elementos ubicados en las tierras de la población, comunas o comunidades indígenas deberá realizar una consulta previa, la cual se caracterizara por ser: "libre e informada, dentro de un plazo razonable, realizado de manera obligatoria y oportuna por las autoridades competentes" que deberá realizarse cuando el Estado este buscando realizar planes o programas de "prospección, explotación y comercialización de recursos no renovables" e implique no solo una afectación ambiental sino también una afectación cultural. Aunado a ello, una vez establecido el plan o proyecto a realizar los afectados podrán "participar en los beneficios que esos proyectos reporten y recibir indemnizaciones por los perjuicios sociales, culturales y ambientales que les causen.”

El capítulo sexto se denomina "Derechos de libertad" refiriéndose en el artículo 66 numerales 1 y 2 a la vida, debiendo entendérsele no solo como el fundamento y la condición de posibilidad de todos los derechos, sino también la protección de una vida digna, puesto que, si los derechos más básicos no son satisfechos no se puede reproducir la vida.

35. Agustín Grijalva, Constitucionalismo en Ecuador, Corte Constitucional para el Período de Transición, (Quito: Corte Constitucional de Ecuador, 2011), 93. 
Así también, en el artículo $66^{\circ}$ si bien se reconocen y garantizan una serie de derechos, esto no significa que se justifica al momento de materializarse el detrimento hacia la sociedad y ambiente, conforme se evidencia en su inciso 15 y 27. En el inciso 15 del artículo 66 señala que los principios rectores al momento de desarrollar actividades económicas son el de solidaridad, responsabilidad social y responsabilidad ambiental. Debiendo entenderse el principio de responsabilidad ambiental en conjunto a lo dispuesto por el inciso 27 del artículo 66 al enunciar que, todos tienen derecho a vivir en un ambiente saludable, que se encuentre libre de contaminación y que este ecológicamente equilibrado, debiendo evidenciarse una situación de armonía para con la naturaleza.

Es decir, no solo la búsqueda de la armonía de las relaciones entre los ciudadanos, sino debe existir una armonía en la relación ser humano - naturaleza, el ser humano capitalista sale de la centralidad, la finalidad ya no es el lucro, se consagra el principio de "armonía con la naturaleza", la naturaleza ya no se concibe como recursos naturales. Por ende, al vivir en armonía con la naturaleza, existen deberes que asume el individuo frente a la conservación y cuidado de la naturaleza, es así como se observa en el artículo 83 incisos 3 y 6 de la Constitución Ecuatoriana los deberes de los ciudadanos ecuatorianos: “3. Defender la integridad territorial del Ecuador y sus recursos naturales. (...) 6. Respetar los derechos de la naturaleza, preservar un ambiente sano y utilizar los recursos naturales de modo racional, sustentable y sostenible."

Los derechos de la naturaleza a los que hace mención el artículo 10 de la Constitución de Ecuador, se encuentran establecidos principalmente en los artículos $71^{\circ}$ al $74^{\circ}$. Así el artículo $71^{\circ}$ establece el derecho de que los ciclos vitales de la Pachamama o la naturaleza sean respetados, aunado a ello también se proclame el respeto a su "existencia y el mantenimiento y regeneración de sus ciclos vitales, estructura, funciones y procesos evolutivos". Evidenciándose el enfoque ecocéntrico, no se habla más de recurso sino se ve a la naturaleza en conjunto. Sin embargo, la naturaleza no puede ejercer por si sola el respeto a sus derechos, por lo que en el segundo párrafo del artículo 71 de la Constitución de Ecuador extiende esta exigibilidad a "toda persona, comunidad, pueblo o nacionalidad". Por último, establece que dentro de las políticas del Estado de Ecuador se deberá incluir programas de incentivos dirigidos a toda la población (personas naturales, jurídicas, y colectivos), cuya finalidad es promover la protección y respeto de la naturaleza y de los elementos que la conforman. Debiendo entenderse a la naturaleza como un todo, donde el ocasionar daño a uno de sus elementos provoca un daño en cadena en todo el ecosistema.

Ahora, ello no significa que el ser humano no pueda realizar su vida en la naturaleza o que el Estado pueda hacer uso de esta, se debe tener en cuenta que la consagración de estos derechos tienen como finalidad evitar el uso abusivo por parte del Estado y de la población, es por ello que el artículo $72^{\circ}$ establece el deber de restauración de la naturaleza, diferenciándolo de las indemnizaciones que deberán pagar los responsables por daños a ecosistemas de lo que dependan individuos o colectivos; es decir la naturaleza debe regenerarse y para ello necesita tiempo sin embargo ante casos donde el Estado y/o personas naturales y jurídicas hayan ocasionado un daño grave o permanente no solo deberán restau- 
rar la naturaleza sino además indemnizar a los colectivos e individuos que "dependan de los sistemas naturales afectados". Por último, el Estado intervendrá ante tal situación para "eliminar o mitigar las consecuencias ambientales nocivas".

El sumak kawsay como principio posee una carga valorativa que representa la multiculturalidad, si bien es criticada en cuanto a cómo debe ser definida, la constitución ecuatoriana brinda elementos para poder entender su significado, conforme estipula el artículo $275^{\circ}$ del texto constitucional ecuatoriano que, el desarrollo del Estado debe ser organizado, dinámico donde confluyen "sistemas económicos, políticos, socio-culturales y ambientales", y sostenible, teniendo como marco el buen vivir del sumak kawsay. Por ende, el desarrollo del país ha de ser planeado asegurando el ejercicio de los derechos propiciando la equidad social, territorial y promover los acuerdos los cuales serán a través de una participación "descentralizada, desconcentrada y transparente", así también el desarrollo del país se realizar acorde a los objetivos del régimen de desarrollo y los principios consagrados en la Constitución. Por último, enfatiza que el buen vivir implica la participación de todos (las personas, comunidades, comunas o pueblos indígenas), no solo es el reconocimiento de derechos sino implica responsabilidad, debiendo tener presente el respeto a la diversidad.

Entendiéndose como un fin del Estado que deberá ser materializado a través de la gestión pública, aplicación de nuevos mecanismos y estrategias para integrar a todos los grupos que alguna vez fueron desplazados y su visión sobre las relaciones del ser humano y el universo.

En palabras de Agustín Grijalva "En cuanto a su concepción económica, la Constitución ecuatoriana no concibe el desarrollo como contradictorio sino como estructuralmente vinculado a un modelo sustentable" ${ }^{36}$. Y en base a esa sustentabilidad es que se toma en cuenta no solo el crecimiento económico sino también la multiculturalidad, las diferencias sociales y la protección de la naturaleza (sumak kawsay y derechos de la naturaleza), sin embargo el crecimiento económico no es nulo, se incentiva conforme se advierte del articulo 284 numeral 2 "incentivar la producción nacional, la productividad y competitividad sistémicas" pero debe ser desarrollado de forma sustentable conforme articulo $276 \mathrm{nu}$ meral 4, para garantizar un acceso equitativo, por último los recursos (agua, aire y suelo) que obtendrá el ser humano debe ser de una calidad óptima.

De acuerdo con lo avanzado, se evidencia que uno de los grandes problemas y propósitos de la Constitución Ecuatoriana es poder llegar a un equilibrio, donde todos los sujetos Estado-sociedad-mercado-naturaleza lleguen a armonizar en sus relaciones. Apreciándose en el artículo 277 inciso 1 donde se garantizan los derechos de "las personas, las colectividades y la naturaleza" y por otro lado el inciso 5. Que versa sobre el desarrollo y promoción de actividades económicas, buscando la armonía en las relaciones Estado-sociedad-mercado-naturaleza.

36. Ibídem, 74. 
Así también, los fines del uso de la tierra son fines sociales (acceso equitativo) y ambientales (bajo principio de equidad, eficiencia y sostenibilidad ambiental), conforme establece el artículo 282 del texto constitucional ecuatoriano.

El artículo $313^{\circ}$ establece que el Estado Ecuatoriano se encargará de la administración de los recursos estratégicos, reconociendo entre ellos al agua, por su alta incidencia en los derechos y el desarrollo social. Sin embargo, con la finalidad de armonizar lo dispuesto en el párrafo anterior con la dimensión cultural y comunitaria del derecho al agua, que se desprende de los principios del buen vivir, en el artículo $318^{\circ}$ reconoce que el agua es primordial para la vida humana y para la naturaleza, y al ser un elemento esencial para la vida no concibe que sea privatizada, por ende la gestión del agua podrá realizarse además de las entidades estatales, de personas jurídicas comunitarias, por ultimo si se pretende dar uso al agua en pos de fines productivos, es el estado quien deberá su autorización.

El capítulo segundo se denomina "biodiversidad y recursos naturales" y posee un apartado específico para referir al agua. Así, la sección sexta incluye dos artículos referidos a la gestión, conservación y manejo del agua, así como criterios de priorización respecto a su uso y los fines generales de la autoridad a cargo de la gestión del agua.

\section{BOLIVIA}

Según Jorge Benavides Ordóñez ${ }^{37}$ A partir del año 2000, las manifestaciones de movimientos indígenas por los recursos naturales ocasionaron que para el año 2005 se consoliden como una fuerza política para que Evo Morales asuma la presidencia. Uno de los movimientos indígenas que han marcado precedente es la "Guerra del Agua" en Cochabamba Carlos Crespo Flores explica las principales causas: "Concesión de la empresa municipal de distribución de agua (SEMAPA) a un consorcio privado internacional, denominado «Aguas del Tunari». La aprobación en el parlamento, de manera no consensuada, de la Ley de Servicios de Agua Potable y Alcantarillado Sanitario (octubre 1999)"38 . En ese entonces, las empresas concesionarias no respetaban las formas en que los pueblos accedían al agua, la monopolización del recurso, la no subvención de servicios básicos, aumentos tarifarios entre otros fueron factores que intervinieron para el levantamiento de la población. Es así como, un 10 de abril del 2000 tomaron la plaza de armas alrededor de $50.000^{39}$ personas.

Recogiendo inspiración de los movimientos de lucha contra la privatización del agua, la Constitución de Bolivia consagra en el artículo $9^{\circ}$ inciso 6 este derecho primero como derecho humano y segundo como un bien que debe ser protegido no solo por el bienestar de la población sino en resguardo del bienestar de generaciones futuras.

37. Jorge Benavides, "Neoconstitucionalismo, Nuevo Constitucionalismo Latinoamericano y Procesos Constituyentes en la Región Andina”, Ius Humani. Revista de Derecho, vol. 5 (2016): 173-188, p. 182.

38. Carlos Crespo, "La guerra del agua en Cochabamba: movimientos sociales y crisis de dispositivos del poder", Debates Ambientales, 20 (2000): 59-70, p. 60.

39. Ibídem. 
No solo se debe garantizar el acceso al agua como servicio, sino que debe responder a estándares de calidad y cantidad. Para evitar futuros conflictos sobre la toma de decisiones en cuanto gestión de recursos, deben existir mecanismos de dialogo para que sean tomados en cuenta todos los afectados. Y conforme, se ha visto el principal problema en cuanto a la toma de decisiones para la gestión del recurso hídrico fue no tomar en cuenta a las comunidades, comunas y pueblos indígenas, por lo que para tratar de remediar tal situación, el artículo $30^{\circ}$ de la Constitución Boliviana establece como derechos de los pueblos indígenas, su participación en la obtención de beneficios producidos de la explotación de sus tierras (inciso 16 del artículo $30^{\circ}$ ) y el derecho de gestionar, usar y aprovechar sus tierras, ello sin perjuicio de derechos adquiridos por terceros, siempre y cuando estos derechos hayan sido adquiridos legítimamente (inciso 17 del artículo $30^{\circ}$ ).

Una normatividad basada en el respeto de la naturaleza, en la conservación de los ecosistemas para generaciones futuras, cabe recordar que las relaciones entre el ser humano y la naturaleza son dinámicas y permanentes, pero deben desarrollarse dentro de parámetros que aseguren su desarrollo. Es así como en el artículo $33^{\circ}$ del texto constitucional boliviano establece el derecho a un medio ambiente sano para las personas, futuras generaciones y demás seres vivos y artículo $108^{\circ}$ estipula que se deberá proteger, defender y usar de forma sustentable los recursos naturales, para futuras generaciones (inciso 15 del artículo $108^{\circ}$ ) y desarrollo de los seres vivos (inciso 16 del artículo $108^{\circ}$ ).

Y es a través de las políticas públicas donde se puede asegurar que el recurso hídrico llegue en óptimas condiciones, siendo encargado exclusivamente el Estado Plurinacional de Bolivia, conforme se puede advertir de los artículos $298^{\circ}, 342^{\circ}, 348^{\circ}, 349^{\circ}, 350^{\circ}, 351^{\circ}, 352^{\circ}, 353^{\circ}$ y $354^{\circ}$. Al ser concebido como recurso de interés público y estratégico para la nación debe ser gestionado por Estado para el desarrollo del país ya sea a través de la concesión a empresas nacionales o extranjeras, no siendo óbice que el Estado a la vez gestione programas en la búsqueda de nuevas tecnologías para un desarrollo sustentable, que se lleven a cabo los procesos de consulta previa, que los afectados participen en los beneficios obtenidos.

Los monopolios y oligopolios privados u otro tipo de acuerdo que pretenda el uso exclusivo y control de bienes y servicios se encuentran prohibidos consagrándose a nivel constitucional. Dado que los recursos son de propiedad del pueblo boliviano y es el Estado el encargado de su administración.

Respecto a su organización económica, Guillermo Arévalo afirma "En Bolivia se impulsó "La Nueva Política Económica” cuyo objetivo principal era lograr la estabilización como requisito para el crecimiento y justicia social" 40

En palabras de Carlos Vacaflores ${ }^{41}$ la Constitución Boliviana establece las bases para un modelo de producción socialista, en este modelo el excedente es distribuido acorde a la necesidad social a diferencia del modelo neoliberal, se caracteriza por:

40. Guillermo Arévalo, “Economía y política del modelo boliviano 2006-2014: evaluación preliminar”, Apuntes del Cenes, 35 (61): 147-174.

41. Vacaflores, Carlos. "La economía plural en Bolivia”, Apuntes, 3 (2017): 1-22. 
- Es el Estado quien enmienda las falencias del mercado

- El Estado es un actor activo en la economía, ya sea como empresario, inversionista, planificador, benefactor, promotor, regulador y banquero.

- La finalidad de gestionar los recursos del Estado es beneficiar a la ciudadanía.

- $\quad$ El Estado pasa de ser exportador primario a industrializador y generador.

- Impulsa tanto la demanda interna como externa

- Reducción del endeudamiento se promueve la inversión interna

- Se generan mayores oportunidades de empleo

- Tiene como punto de partida la estabilidad macroeconómica

Siguiendo con Carlos Vacaflores ${ }^{42}$ Para que el Estado boliviano pase de ser solo un exportador de materias primas, se busca inyectar excedente del sector estratégico al sector generador de empleos e ingresos, pasando a ser un país productor e industrializado. En cuanto a gestión del agua se debe precisar que existen diversas fuentes de agua, por tanto, existen diferentes formas de gestión. Sin embargo, siempre se encuentran basado por Principios culturales locales. Donde la gestión del agua será dependiendo del entorno. Gestionan el recurso de acuerdo con la cosmovisión que tienen del mundo

Los artículos constitucionales que consagran el derecho al agua se encuentran establecidos en un capítulo especial titulado Recursos Hídricos el cual comprende los artículos $373^{\circ}$ al $377^{\circ}$ : En el artículo $373^{\circ}$, reconoce el derecho al agua como derecho fundamental, cuyo uso se realizara a la luz de principios de "solidaridad, complementariedad, reciprocidad, equidad, diversidad y sustentabilidad". Y que en cualquiera de sus estados el agua cumple funciones culturales, sociales y ambientales. No siendo admisible su privatización. En el artículo 374, señala que el uso primordial del agua es para con la vida, por ende, el Estado debe proteger el recurso hídrico a través de una gestión sustentable orientada a su protección, para un acceso equitativo. Así también, se reconoce y protege los usos y costumbres de los pueblos indígenas, reconociéndose la dimensión cultural propia de un país plurinacional. En el artículo $375^{\circ}$, prescribe que, al destinar diferentes usos para el agua, siendo el primordial el destinado para la vida, es el Estado quien a través de su gestión deberá elaborar planes destinados a su "uso, conservación, manejo y aprovechamiento sustentable", respetando los usos y costumbres de las comunidades indígenas. Los glaciales, cuencas y aguas fósiles deben ser protegidas además que, el Estado debe establecer programas para la búsqueda de nuevas fuentes como son las aguas fósiles, para su manejo y protección. En el artículo $376^{\circ}$, se advierte que los ríos, lagos y lagunas que conforman las cuencas hidrográficas son parte de los ecosistemas son recursos estratégicos para el estado por lo que se debe evitar ocasio-

42. Ibídem. 
narles daño y promoverá su preservación. Por último, en el artículo $377^{\circ}$, se reconoce la aplicación de Tratados Internacionales que hayan sido suscritos por el Estado Boliviano entorno a la protección del recurso hídrico. Además, el Estado deberá velar por el bienestar y resguardo de aguas fronterizas y transfronterizas.

\section{VIII. ¿EL FIN DEL PARADIGMA ANTROPOCÉNTRICO?}

El valor de la naturaleza se mide bajo nuestros propios intereses. Mientras se siga viendo a la Naturaleza como un bien jurídico subordinado al ser humano, su valor, alcance, protección, contenido se encuentra condicionado a los intereses del ser humano y a la utilidad que le $\mathrm{da}^{43}$. El déficit ecológico, producto del excesivo consumo de recursos por parte del hombre, ha provocado sobrepasar la biocapacidad del planeta tierra. Producto de ello cada año el consumo de recursos que la tierra puede renovar se va adelantado, conocido como Earth Overshoot Day ${ }^{44}$.

Debiendo replantearse la visión utilitarista y capitalista que se tiene sobre la naturaleza. Fundamentándose en que la naturaleza es una mercancía, un recurso para solventar necesidades humanas, y que debe ser protegido desde una óptica científica, postulando su protección en base a que dicho recurso se puede agotar.

Para Acosta "la Naturaleza vale por sí misma, independientemente de la utilidad o de los usos que le den los seres humanos, y esto es lo que representa una visión biocéntrica. Estos derechos no defienden una Naturaleza intocada que necesite dejar de lado el desarrollo de prácticas agrícola, como: los cultivos, la pesca o la ganadería; estos derechos más bien se posesionan en la defensa de los sistemas de vida, los conjuntos de vida” ${ }^{\prime 5}$. Al reconocer que independientemente del uso que le dé el ser humano, la naturaleza por el hecho de existir posee un valor, puesto es de importancia.

En la actualidad se ven esfuerzos de incorporar institucionalmente tal visión, como son los gobiernos de Ecuador y Bolivia, al reconocer a la Naturaleza como sujeto de derecho. Tanto las Constituciones de Ecuador y Bolivia han reconocido a la Naturaleza como sujeto de derechos destacando tal cambio por parte de ambos estados, quienes han adoptado tal enfoque partiendo desde la visión indígena de sus pueblos.

La inclusión de actores sociales y políticos es primordial puesto deben manifestar sus problemas, aportes y visión con la que conciben la realidad. Pueden surgir dudas respecto a la importancia de un

43. Andrés Badillo, "La judicialización de los derechos de la naturaleza en el Ecuador", (tesis de maestría, Facultad Latinoamericana de Ciencias Sociales -Ecuador, 2013), 12-13.

44. El Día del Overshoot de la Tierra marca la fecha en que la demanda de la humanidad por recursos ecológicos (peces y bosques, por ejemplo) y servicios en un año dado supera lo que la Tierra puede regenerar en ese año. Seguimos aumentando este déficit liquidando el capital natural de la Tierra y acumulando desechos, principalmente dióxido de carbono en la atmósfera. Puede consultarse: https://www.overshootday.org/

45. Citado por Andrés Badillo, “La judicialización de los derechos de la naturaleza en el Ecuador”, op. cit., 21. 
enfoque ecocéntrista proporcionado por la visión indígena de la Naturaleza. Sin embargo, plantea comprender tal visión favorece a la "reconexión" entre ser humano-sociedad y Naturaleza. A través de la ética para la tierra se incluyen a los suelos, agua, flora y fauna como parte del significado de tierra ${ }^{46}$.

En primer lugar, el antropocentrismo puede fundamentar su origen desde una perspectiva religiosa o filosófica, "Ambas sentaron las bases de una concepción antropocéntrica que colocó a nuestra especie por encima de todas las demás, otorgándole autorización para hacer con el mundo natural lo que más conviniera a sus intereses, sin considerar el daño que esto provocaba en la naturaleza y en los organismos que en ella habitan" ${ }^{77}$.

Se entiende por antropocentrismo desde una perspectiva moral como aquella teoría que coloca en el núcleo de la ética los intereses del ser humano, y la valorización de los demás seres, animales y entorno se dará desde la subjetividad del hombre ${ }^{48}$. El lugar que ocupa el ser humano en el cosmos es en el centro, se configura como la especie superior, caracterizada por su capacidad de razonar y actuar (domina a la naturaleza y demás especies). En este sentido, "El ambiente solo debe ser mantenido para proporcionar calidad de vida a la especie humana, en función de la utilidad que le represente” ${ }^{49}$.

Entendiéndose, que el ser humano es la especie dominante por lo que la naturaleza y demás especies han de saciar sus necesidades, en consecuencia, el valor/utilidad de estas será medido en función a las necesidades del ser humano. Ya lo decía Protágoras "el hombre es la medida de todas las cosas". Al hablar de este hombre capitalista y el valor que le da a la naturaleza, desde la visión de Carlos Marx "la riqueza de las sociedades en que impera el régimen capitalista de producción se nos aparece como un “inmenso arsenal de mercancías' y la mercancía como su forma elemental” ${ }^{50}$. El hombre extrae recursos de la Naturaleza, ingresa a un proceso de producción donde él trabaja sobre estas, son intercambiadas en el mercado y cubren necesidades humanas. Por ende, son consideradas mercancías. Se ha mercantilizado la naturaleza y los seres vivos que habitan en ella. Preponderando la visión capitalista antropocentrista de la naturaleza, puesto que es vista como una mercancía puesta para usos y disfruta del hombre.

46. Pablo Ramírez, La Naturaleza como Sujeto de Derechos: Materialización de los Derechos, Mecanismos Procesales y la Incidencia Social en el Ecuador, (Quito: FLACSO, 2012), 33

47. Víctor Salazar y Juan Lariz, "A herencia de la visión antropocéntrica y su origen histórico, obstáculo para el desarrollo sustentable", $20^{\circ}$ Encuentro Nacional sobre Desarrollo Regional en México. Cuernavaca, Morelos del 17 al 20 de noviembre de 2015, 13, acceso el 05 de diciembre de 2019,

https://docplayer.es/90351314-La-herencia-de-la-vision-antropocentrica-y-su-origen-historico-obstaculo-para-eldesarrollo-sustentable.html

48. Vanessa Felipe, “Antropocentrismo y ética ecológica”, (trabajo de fin de grado, Universidad de la Laguna, 2016).

49. Bernardo Soriano, Derechos de la naturaleza; las nociones del antropocentrismo y biocentrismo en las constituciones de México y Ecuador, (México: Universidad Autónoma de Baja California Sur, 2018), 57.

50. Citado por Pablo Ramírez, La Naturaleza como Sujeto de Derechos: Materialización de los Derechos, Mecanismos Procesales y la Incidencia Social en el Ecuador, op. cit., 33. 
En la actualidad, el crecimiento desmesurado de la población, el incremento de necesidades provoca un crecimiento económico irracional, provocando no solo escasez de recursos, sino alteraciones irreversibles al ecosistema ${ }^{51}$, no siendo suficientes las medidas adoptadas por parte de los Estados para la protección de la Naturaleza. De esta forma: "El hombre ha contribuido con el deterioro del ambiente por la ingobernable certidumbre que, como centro vital de la existencia, le ha dado rienda suelta a su capacidad de degradación ambiental, anclado en la concepción antropocéntrica que lo erige como especie superior" ${ }^{\prime 2}$. Ello, nos lleva a repensar la visión con la que se toman las decisiones a nivel personal, institucional y político, por su repercusión, ante ello surge el biocentrismo/ecocentrismo.

El biocentrismo surge a finales de la década de los 70, siendo Arne Naess uno de los más reconocidos representantes ${ }^{53}$, resumiéndose sus principios $^{54}$ en:

- Los seres vivientes que habitan en la tierra poseen un valor intrínseco.

- $\quad$ El ser humano no puede dejar de lado ese valor para la satisfacción de sus necesidades.

- $\quad$ Si bien existe interferencia del ser humano esta no debe ser desmedida ni excesiva.

- Se deben propiciar factores de cambio político, económico y social para un cambio ideológico.

- Es necesario una participación activa para el cambio.

El cambio de enfoque que presenta el biocentrismo precisa no solo un cambio de actitud del ser humano sino la perspectiva con la que él se concibe a la naturaleza repercutiendo en cambio estructurales en la política e instituciones de un Estado.

Como crítica se plantea que se estaría frente a una mera creencia y/o mito, "la integración de la lógica de la naturaleza en la regulación de las conductas humanas constituye para muchos espíritus

51. En América del Sur son 25 las especies animales desaparecidas y en el mundo 79 especies de mamíferos, 23 de reptiles, 36 de anfibios y 134 de aves están extintas. Actualmente, la existencia de 1.143 mamíferos está amenazadas sobre un total de las 5.506 especies del Planeta, según evaluó la International Union for Conservation of Nature (IUCN). Según Fernanda Jara, "El \#10YearChallenge más triste: las especies animales que se extinguieron en la última década”, Infobae, 19 de ene. de 2019, acceso el 10 de diciembre de 2019.

https://www.infobae.com/sociedad/2019/01/19/el-10yearchallenge-mas-triste-las-especies-animales-extintas-en-laultima-decada/

52. Evelyn Ereú, "Del antropocentrismo al biocentrismo: un recorrido hacia la Educación para el desarrollo sostenible", Revista Agrollanía, 2, vol. 16 (2018): 20-25, pp. 21.

53. Vanessa Felipe, “Antropocentrismo y ética ecológica” (trabajo de fin de grado, Universidad de la Laguna, 2016).

54. Citado por Bernardo Soriano, Derechos de la naturaleza; las nociones del antropocentrismo y biocentrismo en las constituciones de México y Ecuador. (México: Universidad Autónoma de Baja California Sur, 2018), 17. 
sensibles de hoy más una creencia - desprovista de elementos metafísicos- que un imperativo racional; esta supuesta novedad se entroncaría con antiguos valores, dogmas y mitos humanos" 55 . No es acaso una simple creencias sin consecuencias prácticas, puesto que nuestro sistema jurídico está basado en creencias, la propia evolución de nuestras instituciones jurídicas se basa en creencias, creemos en el poder de la constitución como norma suprema, caso contrario dicho poder se deslegitimaría.

Las constituciones actuales sobre las que se fundamenta el modelo del Estado Constitucional de derecho contienen una serie de aspiraciones las cuales han sido introducidas como principios y fines por lo que es posible identificar que esta asuma compromisos derivados de creencias respecto a lo que resulta deseable como sociedad y los deberes que debe asumir el Estado.

Para ilustrar el papel de las creencias en un Estado de Derecho siguiendo a Paul Khan "El estado de derecho como una formación cultural existe en el uso que hace el individuo de sus categorías y conceptos en su experiencia. Las creencias y prácticas del derecho son, entones, constitutivos del individuo al mismo tiempo que sostienen a la comunidad política" ${ }^{56}$. Evidenciando que la propia idea de Estado de Derecho encierra un conjunto de creencias.

Presentándose una desconexión entre el hombre y la naturaleza, Lord Ashby, afirma si bien el ser humano se ha reconectado, reconciliado o identificado con él, este aún debe reconciliarse con tres aspectos: "solucionar la creciente escasez de recursos; moderar la demanda de recursos energéticos y materias primas; y la del hombre con los otros hombres" ${ }^{\text {}}$. Dicha reconciliación aún no se ha dado, si bien existen intentos para que el hombre comprenda la magnitud de sus actos y sus consecuencias, la comunidad científica ${ }^{58}$ y sus innumerables investigaciones no han producido el cambio esperado. Jouvenal se preguntaba "si para corregir los errores en que incurrimos por nuestro modo de pensar, no deberíamos devolver a los ríos la jerarquía de personas que se les atribuía en los tiempos paganos" 59 .

La idea de que la naturaleza pueda ser considerada sujeto de derechos pueda hacernos pensar que estamos ante un retroceso, sin embargo, ante los acontecimientos acaecidos en detrimento de la naturaleza, el pensamiento de reconocer a la naturaleza como sujeto de derecho se va reforzando. Ello no significa que se deba ver manera negativa el avance tecnológico, la crítica radica en la relación hombre naturaleza, mientras que esta relación sea vertical, quien seguirá perjudicándose será la naturaleza y los seres que habitan en ella. Al reconocerse los derechos de la naturaleza se reconocen: el ciclo vital

55. Pierre Foy, "Sistema jurídico y naturaleza. Consideraciones sobre el derecho y la naturaleza”. Revista Derecho PUCP, 74 (2015): 485-517, 487.

56. Daniel Bonilla, "El análisis cultural del derecho. Entrevista a Paul Kahn”. Isonomía, 46 (2017): 131-154, p. 139.

57. Citado por Pierre Foy, "Sistema jurídico y naturaleza. Consideraciones sobre el derecho y la naturaleza”, op. cit., 486.

58. Grupo Intergubernamental de Expertos sobre el Cambio Climático, IPCC (Intergovernmental Panel on Climate Change) en su Cuarto Informe de Evaluación del Panel Intergubernamental sobre Cambio Climático, acceso el 10 de diciembre de 2019, https://www.ipcc.ch/site/assets/uploads/2018/02/ar4_syr_sp.pdf

59. Citado por Pierre Foy, “Sistema jurídico y naturaleza. Consideraciones sobre el derecho y la naturaleza”, op. cit., 486. 
de las especies, el cual se desarrolla conforme esta se desenvuelva en su entorno; el aprovechamiento de la tierra no debe propiciar la destrucción de estos ciclos vitales ni la extinción de las especies ${ }^{60}$. En consecuencia, debemos reajustar la forma en que intervenimos y damos uso de la tierra reajustándolo a los ritmos de la naturaleza. Lo que se pretende es propiciar una relación horizontal para asegurar el respeto a la naturaleza.

El Perú es participe en un considerable número de tratados ${ }^{61}$, pactos y/o compromisos sin embargo como es típico de los países latinoamericanos se tiene una forma de pensar respecto a la consagración de los derechos, se tiende a una estrategia acumulativa, en consecuencia, para que se tutele un derecho (haciendo referencia a los derechos económicos sociales y culturales) debe estar reconocido en la constitución, produciendo una suerte de acopio descontrolado de derechos. Encajar estos enfoques si bien resulta complejo al ser un Estado pluricultural se debe brindar los canales necesarios para que las comunidades indígenas y su cosmovisión de la naturaleza puedan participar y solicitar resguardo, deben crearse espacios que propicien el dialogo intercultural.

\section{DERECHO DEL MEDIO AMBIENTE Y DERECHOS DE LA NATURALEZA}

Si bien existe normativa nacional e internacional respecto a la protección del medio ambiente se debe tener en cuenta la diferencia entre la concepción de medio ambiente y naturaleza para el derecho.

En primer lugar, se debe entender como derecho ambiental como el conjunto de normas que tienen como finalidad la defensa del medio ambiente humano ${ }^{62}$. Serrano sostiene que:

el Derecho ambiental no regula los sistemas ambientales. Primero, porque el medio ambiental no es un sistema, sino un entorno. Y segundo, porque — aun admitiendo, lo cual no es lo mismo, que sí hay sistemas ecológicos o ecosistemas en el entorno de los sistemas sociales- lo que regula el Derecho no es el transcurso de un río, ni los movimientos migratorios de las aves — todo eso se [sic] solo—, sino las conductas individuales, las prácticas sociales y las intervenciones públicas relevantes para el transcurso de los ríos o los movimientos de las aves ${ }^{63}$.

De lo expresado se denota el enfoque antropocéntrico, el medio ambiente es concebido como aquel espacio/lugar donde el ser humano habrá de desarrollarse, no se hace diferencia en los ecosistemas que se desarrollan en él, usándose el mismo significado para los significantes medio ambiente y ecosistema.

60. Mónica Naranjo, "Derechos de la Naturaleza y la Gestión de la Defensoría del Pueblo de Ecuador", (tesis de maestría, FLACSO, 2016), 15.

61. La Constitución Política del Perú en su Capítulo II, De los Tratados, Art. 55, establece que: "Los tratados celebrados por el Estado y en vigor forman parte del derecho nacional".

62. La Constitución Política del Perú en su Capítulo II, De los Tratados, Art. 55, establece que: “Los tratados celebrados por el Estado y en vigor forman parte del derecho nacional”.

63. Citado por Pierre Foy, "Sistema jurídico y naturaleza. Consideraciones sobre el derecho y la naturaleza", op. cit., 486. 
Si bien en algunos casos se trata de tomar parte de la visión biocéntrica, por ejemplo la Convención sobre el Comercio Internacional de Especies Amenazadas de Fauna y Flora Silvestre (CITES), Convención Sobre Humedales de Importancia Internacional Especialmente como Hábitat de Aves Acuáticas (RAMSAR), Convenio de Diversidad Biológica (CDB), Convención para la Protección de la Flora, de la Fauna y de las Bellezas Escénicas Naturales de los Países de América, Convención Sobre la Conservación de Especies Migratorias de Animales Silvestres (CMS), donde se aborda la protección de la naturaleza tomando un punto de vista biocéntrico puesto que se tratan puntos referentes a la protección de ecosistemas y biodiversidad. Entendiéndose que si bien el ser humano es consiente que el medio ambiente va más allá del lugar donde se desarrolla, puesto que presenta un conjunto de ecosistemas, en la práctica no los concibe como un todo, sino que bajo la teoría jurídica va desmembrando y generando expresiones jurídicas materializándose en múltiples disposiciones normativas que las regularan (agua, bosques, mares, ríos, flora, fauna, etc.)

Las dinámicas entre hombre naturaleza conforme plantea la teoría jurídica clásica es hombre recurso manifestándose a través de normas que regulan el agua, mares, bosques, etc. Sin embargo, cada relación conlleva un impacto al ambiente. La problemática radica que, al no tener esta visión en conjunto, empezamos a referirnos solo a infracciones normativas de terminados recursos, elementos identificados individualmente ${ }^{64}$.

Las diferencias de las normas que son antropocéntricas y biocéntricas, son sustentadas en "la relación de una especie con su entorno, resaltando que a diferencia del derecho ambiental, no se trata de demostrar la infracción a una norma ambiental, sobrepasando un límite máximo o impactando determinado organismo, sino que la prueba debe concretarse en demostrar el irrespeto a alguno o varios de los elementos protegidos por la norma (ciclos vitales, estructura, funciones y procesos evolutivos)." 65 El derecho ambiental busca tutelar el medio ambiente teniendo como base normas ambientales, en cambio el significado que encierra el término naturaleza encierra es mucho más amplio, siendo que al vulnerarla se configuran situaciones pluriofensivas.

Aunado a ello la mayoría de Los estados (exceptuando a Ecuador y Bolivia) el derecho ambiental encierra un enfoque dual (derecho ambiental -derecho al desarrollo). Naranjo Rivas describe que:

el sentido es la protección ambiental considerando adicionalmente el derecho al desarrollo, por tanto gran parte de la normativa ambiental tiene este enfoque dual, que en la práctica resultó una limitante para la protección efectiva de la naturaleza, prueba de ello es el incremento de la conflictividad generada por razones de su explotación y/o contaminación, esto no quiere decir que el derecho ambiental haya sido ineficaz, por el contrario, desde su surgimiento ha evolucionado jurídicamente y sea convertido en

64. Ibídem.

65. Víctor Salazar y Juan Lariz, "A herencia de la visión antropocéntrica y su origen histórico, obstáculo para el desarrollo sustentable", op. cit., 40. 
el medio a través del cual la naturaleza se ha transformado ideológicamente desde un objeto hasta un sujeto de protección ${ }^{66}$.

Entendiéndose a la declaración de los derechos de la Naturaleza como el siguiente paso para superar el derecho ambiental.

Si bien puede parecer irreconciliable el derecho a un medio ambiente saludable y el derecho al desarrollo, dado que el derecho al desarrollo implica la realización e implementación por parte del Estado de políticas extractivas, mientras que el derecho ambiental visto desde una óptica biocéntrica sostiene la defensa de la naturaleza, genera un debate amplio que hoy en día sigue generando revuelo ${ }^{67}$. Referirnos a la naturaleza como sujeto de derecho resalta la no pertenencia de esta para con el ser humano, en palabras de Naranjo "la naturaleza no le pertenece al ser humano, el ser humano pertenece a la naturaleza, por ello, la naturaleza no debe ser considerada como un medio, pues en su esencia es un fin, y es por tanto un sujeto de derechos; se debe considerar que la protección de la naturaleza asegura su uso intergeneracional desde una perspectiva completa de desarrollo sostenible." ${ }^{\prime 8}$

Ello no implica una disminución de los derechos individuales sino todo lo contrario, debemos tener presente que una de las características de los derechos humanos es la no jerarquización y la interrelación, en base a esto debemos comprender que en la interioridad de los derechos individuales se encuentran los derechos económicos sociales y culturales, no pudiendo descartarse las visiones holísticas de la naturaleza con la que las colectividades se identifican, toda vez que el colectivo es una de las formas en que el individuo puede desarrollarse en plenitud sus posibilidades.

\section{DERECHO AL AGUA COMO DERECHO FUNDAMENTAL EN EL PERÚ:}

El Tribunal Constitucional ha reconocido con anterioridad el derecho al agua como derecho fundamental ${ }^{69}$ a través de la cláusula de derechos no enumerados del artículo 3 de la Constitución, sin embargo, al haber sido desarrollado a través de la jurisprudencia constitucional motivó a que el Congreso apruebe una Ley de reforma constitucional que lo incorpora expresamente al texto constitucional ${ }^{70}$.

Como advertimos anteriormente, en los fundamentos $21^{\circ}$ de la sentencia $N^{o} 06534-2006-\mathrm{AA}^{71}$,

66. Mónica Naranjo, “Derechos de la Naturaleza y la Gestión de la Defensoría del Pueblo de Ecuador”, op. cit., 28.

67. Andrés Badillo, "La judicialización de los derechos de la naturaleza en el Ecuador", (tesis de maestría, Facultad Latinoamericana de Ciencias Sociales -Ecuador, 2013), 69.

68. Mónica Naranjo, “Derechos de la Naturaleza y la Gestión de la Defensoría del Pueblo de Ecuador”, op. cit., 29.

69. Sentencias recaídas en los Expedientes $\mathrm{N}^{\circ}$ 2064-2004-AA/TC y Nº 6534-2006-PA/TC.

70. Richard Llacsahuanga y Juan Carlos Díaz Colchado, Mesa Temática N²: El derecho fundamental al agua. Presentación, 09 de oct. de 2017, p. 2, acceso el 10 de diciembre de 2019,http://themis.pe/wp-content/uploads/2017/09/Mesa-2. docx

71. Sobre lo expuesto en la sentencia recaída en el Exp. Nº6534-2006-PA/TC, Lima, caso Santos Eresminda Távara Ceferino. 
el TC advirtió que el derecho al agua debe de satisfacerse garantizando el acceso, la calidad y la suficiencia del recurso. Esto debería llevar a que el Estado debe asegurar: la salvaguarda del recurso hídrico en base a lineamientos orientados ,por ejemplo, a partir de su relación con el derecho a la salud; debe garantizar una adecuada gestión del recurso y debe existir una entidad encargada de su supervisión con independencia $^{72}$

En el fundamento $22^{\circ}$ el Tribunal Constitucional estableció que el Estado debe garantizar las condiciones que permitan acercar a los destinatarios al recurso hídrico, lo que puede realizar directa o indirectamente (por ejemplo, a través de concesionarios. Para ello, debe cumplir con ciertas condiciones: a) garantizar la existencia del agua, las instalaciones y servicios cerca al lugar donde las personas realizan sus principales actividades (residencia, trabajo, estudios, etc.), b) garantizar que aquellas sean plenamente accesibles económicamente para cualquier persona, solo permitiéndose una diferenciación en términos de mejora o especialización del servicio cuando su habilitación requiera una mayor inversión, c) por lo que no se admite ningún tipo de discriminación cuando se debe garantizar las condiciones de igualdad en el suministro del agua, debiendo el Estado prestas especial atención a los sectores más vulnerables, y d) por último, debe desarrollar una política de promoción de información sobre la necesidad de protección del agua como recurso natural y su uso.

Por lo que el Estado creará, ya sea directa o indirectamente, las condiciones necesarias para que las personas tengan acercamiento a fuentes de agua potable, ello no quiere decir que todas las personas tengan este servicio en sus hogares, sino que las fuentes de agua potable se encuentren próximas a estas, según la OMS debe ser a una distancia no mayor a 1000 metros del hogar, siendo el tiempo necesario para su búsqueda no mayor a 30 minutos $^{73}$. Según el Comité sobre los DESC de la ONU, se debe hacer la diferencia entre accesibilidad física y accesibilidad económica. La primera, se refiere a que debe accederse al recurso en cantidad suficiente y aceptable dentro o en la proximidad inmediata a cada casa, institución educativa o laboral. Por su parte, la accesibilidad económica consiste en que las personas tengan la capacidad económica de acceder al recurso, las instalaciones y servicios, así como que los gravámenes relacionados con la seguridad del recurso deben ser razonables ${ }^{74}$.

En el fundamento 23 de la referida sentencia, el TC advierte sobre la calidad. Esto significa que se debe garantizar en plenitud las condiciones de salubridad y mantener en condiciones óptimas el servicio y las instalaciones en tanto al ser indispensable para la vida resulta inaceptable que ésta pueda poner en peligro la vida, salud o seguridad de las personas. Para ello, debe adoptar medidas de preven-

72. C. Soriano, Y. Jacobo y J. Núñez, "El Reconocimiento Constitucional del Derecho al Agua en el Salvador" (tesis de grado, Universidad de El Salvador, 2012), 27.

73. Organización Mundial de la Salud, "El Derecho al agua", folleto Informativo No 35, 2011, acceso 10 de diciembre de 2019, https://www.ohchr.org/Documents/Publications/FactSheet35sp.pdf

74. Organización de las Naciones Unidas, Comité sobre los Derechos Económicos, Sociales y Culturales, Observación General N ${ }^{\circ}$. 15, acceso 10 de diciembre de 2019, https://www.acnur.org/fileadmin/Documentos/BDL/2012/8789.pdf 
ción contra la contaminación o que puedan resultar perjudiciales en tanto recurso natural, así como el deterioro natural y tomar acciones cuando sea necesario sustituir las instalaciones o servicios por otros que permitan ofrecer un servicio igual o mejorar los estándares de calidad.

$\mathrm{Al}$ respecto, el Comité sobre los DESC de la ONU ha señalado que el agua para uso personal o doméstico debe estar libre de microorganismos, químicos o peligros radiológicos que puedan amenazar la vida o la salud de las personas; asimismo debe garantizar que posea un color, gusto y olor aceptable. El Estado debe remitirse a las guías para la calidad del agua potable emitidas por la OMS, las cuales contienen los criterios y opiniones oficiales del sistema de las Naciones Unidas sobre temas relacionados a la calidad del agua y la salud.

Conforme indica el Sistema Nacional de Información Ambiental"5 , el concepto de "Calidad de Aguas" se asociaba al agua apta para el consumo humano, pero a raíz del desarrollo y expansión de asentamientos humanos por todo el Perú, el concepto de calidad de agua se ha ampliado; en la actualidad la calidad del agua para el consumo humano no es la misma que para el riego de cultivos, es decir existe un sin número de actividades humanas donde se utiliza el agua, por lo que el uso en una actividad particular puede no ser apta para otro, no existiendo "un criterio único de calidad para cualquier fin".

Según el Sistema Nacional de Información Ambiental, para los usos importantes y comunes del agua, se considera de buena calidad si posee los siguientes requisitos respecto a las concentraciones bajo diversos parámetros fisicoquímicos:

Físicos: sabor y olor, color, turbidez, conductividad, temperatura.

Químicos: pH, O2, saturación de oxígeno, sólidos en suspensión, cloruros, sulfatos, nitratos, fosfatos, amoniaco sulfuros, hierro, manganeso, metales pesados, gases disueltos como dióxido de carbono, etc., DBO5, DQO.

Biológicos: Bacterianos (presencia de bacterias coliformes, indicadoras de contaminación fecal y otras como Salmonellas, etc.); presencia de virus.

Comunidades de macroinvertebrados bentónicos: son indicadores de buena calidad del agua en función de las especies más o menos tolerantes a la contaminación que aparezcan ${ }^{76}$.

Es necesario entender la importancia de asegurar la calidad del agua, sobre todo en entornos "menos desarrollados" toda vez que, en estos países, un alto número de enfermedades son transmitidas mediante el agua ${ }^{77}$.

75. Sistema Nacional de Información Ambiental, "Monitoreo de la calidad de agua de los ríos en el Perú", acceso 10 de diciembre de 2019, https://www.sinia.minam.gob.pe/tematica/parametros-calidad-agua-dulce

76. Ibídem.

77. Citado por C. Soriano, Y. Jacobo y J. Núñez, “El Reconocimiento Constitucional del Derecho al Agua en el Salvador" (Tesis de grado. Universidad de El Salvador, 2012), 25. 
El fundamento 24 de la referida sentencia, se refiere a la suficiencia. La suficiencia alude a que el recurso debe brindarse en cantidades adecuadas que permitan satisfacer sus necesidades básicas, así como aquellas referidas a sus usos personales y domésticos, enfatizando aquellos ligados a la salud, por lo que debe garantizarse que sea brindado en cantidades que permitan satisfacer las exigencias básicas de las personas.

Según el Comité sobre los DESC, la suficiencia, también llamada disponibilidad, se trata, de garantizar a las personas que el agua potable les sea suficiente para su uso personal y doméstico y para prevenir enfermedades. Esos usos ordinariamente incluyen su consumo, la preparación de alimentos, el higiene personal y familiar, lavado de ropa, saneamiento personal ${ }^{78}$. En este sentido, al ser un derecho humano tan importante, debe prestarse especial atención a que se preste el servicio en cantidades suficientes especialmente a aquellas comunidades que se encuentren en situación de pobreza, pues esto puede poner en peligro su propia existencia y desarrollo; así su desatención puede acarrear una serie de conflictos políticos en el orden nacional e internacional

Como se ha establecido en la Sentencia recaída en el Exp. № 1671-201, expedido por la Sala Constitucional de Lambayeque, la intervención del juez constitucional requiere la identificación del contenido constitucionalmente protegido, por lo que en su fundamento segundo sostiene: "Si se vulnera el contenido constitucionalmente protegido del derecho fundamental, es exigible la tutela urgente del juez constitucional. Sin embargo, si se vulnera dicho derecho en sus contenidos no esencial o adicional, las pretensiones deben ser declaradas infundadas o improcedentes".

De esta forma, las garantías se entienden como mecanismos que posibilitan asegurar la eficacia de los derechos ${ }^{79}$ Por lo que, la reciente incorporación el artículo 7-A en la Constitución Política del Perú, ha generado que se empiecen a presentar las primeras demandas de amparo que reclaman al estado la tutela de este derecho humano. Un caso reciente, es la demanda de amparo presentada por Katia Gilvonio, Marisa Glave y José Antonio De Echave con el Ministerio de Energía y Minas contra el acto administrativo que aprueba el Estudio de Impacto Ambiental del Proyecto Ariana autorizando la construcción de una planta de procesos metalúrgicos, un depósito de relaves e instalaciones auxiliares. Los demandantes alegan que dicho proyecto viola el artículo $7^{\circ}$-A (derecho al agua), el artículo $2^{\circ} .22$ de la Constitución (disfrutar de un medio ambiente equilibrado), y el artículo $7^{\circ}$ (derecho a la salud) de la Constitución Política del Perú, en tanto colocan en peligro los ecosistemas de las lagunas Huancash, Pucrococha y Shiusha en la cuenca del Río Rímac, de donde deriva el agua que se transporta para el consumo de los ciudadanos de Lima y el Callao, e incluso pone en riesgo futuro proyecto Marca V que

78. Organización de las Naciones Unidas, Comité sobre los Derechos Económicos, Sociales y Culturales, Observación General N. 15, acceso 10 de diciembre de 2019, https://www.acnur.org/fileadmin/Documentos/BDL/2012/8789.pdf

79. Organización de las Naciones Unidas, Comité sobre los Derechos Económicos, Sociales y Culturales, Observación General N. 15, acceso 10 de diciembre de 2019, https://www.acnur.org/fileadmin/Documentos/BDL/2012/8789.pdf 
trasvasaría en un futuro el agua potable hacia Lima al aportar estas lagunas agua al río Carispaccha ${ }^{80}$.

En dicho caso, se está solicitando la tutela del derecho al agua en lo referido a las garantías del acceso para el consumo humano en un espacio donde habita fundamentalmente población urbana. Sin embargo, la cuestión se complica, si agregamos otras variables y exploramos otras situaciones problemáticas que afectan a otros grupos humanos y que se producen en espacios fundamentalmente rurales.

Por ejemplo, pese a que el artículo 7-A ha sido introducido en la Constitución Política del Perú ha sido introducido en el año 2017, hasta la fecha persisten los pasivos ambientales de operaciones minera e hidrocarburíferas, daños que se han generado en algunos casos antes de dicho reconocimiento pero que siguen generando contaminación a las fuentes de agua de comunidades y poblaciones indígenas. Por lo que el Estado poco o nada ha hecho para revertir esta situación de vulneración colectiva de derechos, como el derecho a la salud, por lo que además de no tener acceso a la atención de salud adecuada para atender la afectación por metales tóxicos, no cuentan con el acceso al agua potable apta para consumo humano ${ }^{81}$.

Uno de estos casos es el de Chiriaco (2016), en donde se produjo una fuga de 3000 barriles de petróleo perjudicando a los niños que fueron contratados de manera negligente para labores de limpieza, así como a 243 personas que se identificaron fueron expuestas a este elemento sin protección. En el mismo sentido se puede hablar de Cuninico (2014), donde ocurrió un derrame similar de casi 3000 mil barriles de petróleo; sin embargo, los casos emblemáticos son los de las cuencas de los ríos Corrientes, Marañón, Pastaza y Tigres los cuales llevan más de 40 años siendo expuestos a sustancias tóxicas producto de los derrames ${ }^{82}$.

Es así como, frente a la violación de la consulta previa y la afectación de otros derechos relacionados con el derecho al agua de los pueblos indígenas en el Perú, el 19 de agosto de 2019, se firma el Pacto de Unidad de las Organizaciones Nacionales Indígenas, en el marco del Día Internacional de los Pueblos Originarios, el cual en lo que respecto a las demandas relativas a su derecho humano al agua señalan lo siguiente:

11. RESPALDAMOS Y EXIGIMOS al Estado el cumplimiento efectivo de la primera sentencia que declara la NULIDAD de 127 concesiones mineras, predios agrícolas y derechos de agua dados a terceros SIN CONSULTA PREVIA dentro de la Comunidad Tres Islas (Madre de Dios), y que ordena descontaminación, reparación del hábitat; atención de la salud y agua segura.

80. Instituto de Defensa Legal, "Litigio constitucional en defensa del agua potable de Lima”, IDL, 31 de may. de 2019 , acceso 10 de diciembre de 2019, https://idl.org.pe/litigio-constitucional-en-defensa-del-agua-potable-de-lima/

81. Centro Amazónico de Antropología y Aplicación Práctica, "Pueblos indígenas en el Perú: Falta mucho para lograr el ejercicio pleno de sus derechos". CAAP, 09 de ago. de 2019, acceso 10 de diciembre de 2019,

http://www.caaap.org.pe/website/2019/08/09/pueblos-indigenas-en-el-peru-falta-mucho-para-lograr-el-ejercicio-

pleno-de-sus-derechos/

82. “¿El Estado peruano cumple los derechos de los pueblos originarios?”, Portal Web CoperAcción, 23 de oct. de 2018, acceso 10 de diciembre de 2019,

http://cooperaccion.org.pe/el-estado-peruano-cumple-los-derechos-de-los-pueblos-originarios/ 
12. EXIGIMOS que se convierta en POLÍTICA PÚBLICA: la NULIDAD de actos inconsultos, como las concesiones mineras, lotes petroleros, licencias de agua y otros; la RESTITUCIÓN colectiva de los territorios despojados; la descontaminación, reparación de pasivos e impactos ambientales; la atención de la salud y la garantía de agua y alimentación segura.

13. Así, por ejemplo, exigimos la NULIDAD (y no sólo la suspensión o paralización temporal) de las concesiones mineras inconsultas, cuya imposición violenta ha causado muertos y heridos, y criminalización de dirigentes, como Conga, Tía María, Cañariaco, y las demás. Igualmente, exigimos la nulidad del Lote 64 y demás lotes petroleros establecidos sin consulta previa; la reparación de los derrames, la descontaminación de aguas y suelos, y la atención de la salud ${ }^{83}$.

En este sentido, conviene anotar que el derecho al desarrollo no solo como derecho individual sino como derecho colectivo, el Estado materializa este derecho a través de sus políticas procurando el bienestar social, sin embargo no debemos olvidarnos que en el derecho al desarrollo también están inmersos los derechos civiles y políticos y además los económicos sociales y culturales, siempre partiendo desde un punto de vista antropocéntrico y por ende al confrontarse con el derecho al medio ambiente en la gran mayoría de casos son las normas ambientales las que terminan cediendo, razón por la cual se producen tantas controversias. Es por ello que, no sorprende que en el Perú se hayan otorgado tantos permisos de uso de aguas en zonas de riesgo de sequías en diversas regiones del Perú ${ }^{84}$.

\section{CONCLUSIONES}

El Nuevo Constitucionalismo Latinoamericano tiene como origen procesos constituyentes en América Latina, impulsados por los movimientos sociales en países como Bolivia y Ecuador. Estos grupos reclamaban el cese de la postergación y el fin de la exclusión sufrida a través de la historia colonial y republicana, siendo los grupos indígenas quienes actores importantes en dichos procesos. Sin embargo, la pluralidad cultural de los países latinoamericanos llevó a estos grupos a dialogar respecto a la manera en la que el Estado podría garantizar la convivencia entre los individuos y los pueblos. Es así como se identifica como uno de los factores que sostienen y permiten la reproducción de un sistema de desigualdad y exclusión social, a las ideas que sostienen a la modernidad occidental capitalista: la racionalidad costo-beneficio.

Frente a ello, los pueblos indígenas, a través de las experiencias compartidas, proponen un modelo alternativo de desarrollo basado en los principios que han regido ancestralmente su vida comunitaria.

83. IIDS/IILS. "Pacto de Unidad de las Organizaciones Nacionales Indígenas se pronuncia en el marco del Día Internacional de los Pueblos Originarios”, La Mula, 19 ago. de 2019, acceso 10 de diciembre de 2019, https://alertanetiids.lamula.pe/2019/08/19/pacto-unidad-de-las-organizaciones-nacionales-indigenas-sepronuncia-en-el-marco-del-dia-internacional-de-los-pueblos-originarios/alertanet/

84. Elizabeth Salazar, “Mineras extraen agua de zonas en riesgo de sequía”. Portal Ojo Público, 02 de feb. de 2018, acceso 10 de diciembre de 2019, https://duenosdelagua.ojo-publico.com/especiales/mapadelagua/ 
Estos principios se denominaron "los principios del buen vivir", los cuales se basan en una relación armónica entre ser humano y naturaleza, rompiendo la visión antropocéntrica predominante. Es así, que ese fue el punto de partida para incorporar una serie de innovaciones en la Constituciones de Ecuador y Bolivia.

Dentro de las innovaciones más importantes y la que ha tenido mayor repercusión respecto a la gobernanza ambiental, ha sido la elevación de la naturaleza al estatus de sujeto de derechos. Ello se explica, toda vez que para armonizar es necesario igualar las condiciones y anular la posición hegemónica en la que se encuentra el ser humano respecto a la naturaleza, al tener esta el estatus de objeto. Así, la consagración de derechos de la naturaleza en ambas constituciones, legitima a la ciudadanía a exigir tutela judicial efectiva frente a la vulneración de los derechos de la naturaleza de la misma manera en la que se exigiría frente a una violación de derechos humanos.

La consagración del derecho al agua potable en el Perú, si bien resulta un avance importante en materia de derechos económicos y sociales, ha dejado de lado la dimensión cultural de este derecho.

Es así como el reconocimiento de este derecho en el artículo 7-A de la Constitución Política del Perú, se refiere principalmente al acceso a los servicios de saneamiento y agua potable, garantizando el uso para fines domésticos. Sin embargo, en dicho artículo no se incluye de manera expresa su dimensión sociocultural, por lo que no resulta por sí misma un aporte significativo para la resolución de los conflictos que se producen entre los derechos de las empresas privadas que realizan actividades extractivas y los derechos de los pueblos indígenas.

Esta respuesta podría hallarse de una interpretación sistemática del derecho al agua, reconociendo las obligaciones del Estado de proteger el medioambiente y a los pueblos indígenas a través de mecanismos como la consulta previa (Convenio 169 de la OIT). Sin embargo, la incorporación expresa de esta dimensión del derecho al agua en incorporación del artículo 7-A pondría de realce la fuerza normativa de dichos derechos de origen convencional y las obligaciones del Estado, por lo que se deja la puerta abierta a que persistan las vulneraciones de derechos de los pueblos indígenas ante la falta de voluntad política de las autoridades. Asimismo, las carencias institucionales podrían corregirse a través de figuras como la declaración de inconstitucional por omisión y la exhortación y la facultad de exhortar a los órganos públicos encargados del desarrollo de las políticas públicas que permitan el goce del derecho al agua de los pueblos indígenas, extendiendo la interpretación del artículo 7-A para hacerlo compatible con los instrumentos internacionales que versan sobre la materia.

A modo de comparación, las Constituciones del Nuevo Constitucionalismo Latinoamericano, contienen un desarrollo mucho más amplio del derecho al agua, el cual se ve atravesado a través de todo su desarrollo por la noción de "buen vivir", lo que exige que el Estado no solo debe actuar sobre la administración del recurso, sino que esta actuación debe realizarse de manera armoniosa con el medio ambiente y en base al respeto a las cosmovisiones tradicionales y las prácticas culturales de los pueblos indígenas, advirtiendo que estos derechos son la base del desarrollo económico, debiendo este adecuarse a ellos y no viceversa. 


\section{REFERENCIAS}

- Acosta, Alberto. "Hacia la Declaración Universal de los Derechos de la Naturaleza Reflexiones para la acción”. Revista de la Asociación de Funcionarios y Empleados del Servicio Exterior Ecuatoriano. 54 (2008):11-30.

- Acosta, A. y Martínez E. La Naturaleza con Derechos de la filosofía a la política. Quito: Ediciones Abya-Yala, 2011.

- Arévalo. Guillermo. "Economía y política del modelo boliviano 2006-2014: evaluación preliminar". Apuntes del Cenes, 35(61): 147-174. https://doi.org/10.19053/22565779.4152

- Asamblea Nacional de la República de Ecuador. La Constitución de Montecristi, un sueño colectivo, el cambio hacia el buen vivir. Quito: Asamblea Nacional de la República de Ecuador, 2010.

https://issuu.com/direccion.comunicacion/docs/memorias_asamblea_constituyente; pág. 16.

- Badillo, Andrés. "La judicialización de los derechos de la naturaleza en el Ecuador". Tesis de Maestría. Facultad Latinoamericana de Ciencias Sociales -Ecuador, 2013.

- Bedón, René. “Contenido y aplicación de los derechos de la naturaleza”. Ius Humani, vol. 5 (2016): 133-148. https://doi.org/10.31207/ih.v5i0.124

- Belloso, Nuria. “El Neoconstitucionalismo y el 'Nuevo' Constitucionalismo Latinoamericano: ¿Dos corrientes llamadas a entenderse?” Cuadernos Electrónicos de Filosofia del Derecho, 32 (2015): 21-53.

- Benavides, Jorge. "Neoconstitucionalismo, Nuevo Constitucionalismo Latinoamericano y Procesos Constituyentes en la Región Andina”. Ius Humani, Revista de Derecho, vol. 5 (2016): 173-188. https://doi.org/10.31207/ih.v5i0.99

- Bonilla Maldonado, Daniel. "El análisis cultural del derecho. Entrevista a Paul Kahn". Isonomía, 46 (2017): 131-154. https://doi.org/10.5347/46.2017.55

- Cooperacción. “¿El Estado peruano cumple los derechos de los pueblos originarios?” Portal Web CoperAcción, 23 de oct. de 2018. http://cooperaccion.org.pe/el-estado-peruano-cumple-los-derechos-de-los-pueblos-originarios/

- Centro Amazónico de Antropología y Aplicación Práctica. "Pueblos indígenas en el Perú: Falta mucho para lograr el ejercicio pleno de sus derechos". CAAP, 09 de ago. de 2019. http://www.caaap.org.pe/website/2019/08/09/pueblos-indigenas-en-el-peru-falta-mucho-paralograr-el-ejercicio-pleno-de-sus-derechos/ 
- Crespo, Carlos. "La guerra del agua en Cochabamba: movimientos sociales y crisis de dispositivos del poder". Debates Ambientales, 20 (2000): 59-70.

- Ereú, Evelyn. "Del antropocentrismo al biocentrismo: un recorrido hacia la Educación para el desarrollo sostenible”. Revista Agrollanía, 2, vol. 16 (2018): 20-25.

- Felipe, Vanessa. "Antropocentrismo y ética ecológica”. Trabajo de fin de grado. Universidad de la Laguna, 2016.

- Figueroa, Edwin. “Contenido Constitucionalmente Protegido de un Derecho Fundamental: Reglas para su Determinación”, 2014.

https://edwinfigueroag.wordpress.com/2014/04/16/derechos-fundamentales-el-contenidoconstitucionalmente-protegido-articulo/

- Foy, Pierre. "Sistema jurídico y naturaleza. Consideraciones sobre el derecho y la naturaleza". Revista Derecho PUCP, 74 (2015): 485-517.

- Gilmeno, Fernando. "El rostro Harakmbut, redescubierto como arma indígena ante la deforestación”. La Información. (26 de feb. de 2016)

https://www.lainformacion.com/economia-negocios-y-finanzas/el-rostro-harakmbut-redescubiertocomo-arma-indigena-ante-la-deforestacion_ qcsO5Te2eXHjMzoMmSw6X1/

- Gudynas Eduardo. Desarrollo, derechos de la naturaleza y buen vivir después de Montecristi. Quito: Centro de Investigaciones Ciudad y Observatorio de la Cooperación al Desarrollo, 2011.

- Grijalva, Agustín. Constitucionalismo en Ecuador, Corte Constitucional para el Período de Transición. Quito: Corte Constitucional de Ecuador, 2011.

- Huanacuni, Fernando. Buen Vivir / Vivir Bien: Filosofí, politicas, estrategias y experiencias regionales andinas. Lima: Coordinadora Andina de Organizaciones Indígenas - CAOI, 2010.

- $\quad$ IIDS/IILS. "Pacto de Unidad de las Organizaciones Nacionales Indígenas se pronuncia en el marco del Día Internacional de los Pueblos Originarios”. La Mula, 19 ago. de 2019. https://alertanetiids.lamula.pe/2019/08/19/pacto-unidad-de-las-organizaciones-nacionalesindigenas-se-pronuncia-en-el-marco-del-dia-internacional-de-los-pueblos-originarios/alertanet/

- Instituto de Defensa Legal. "Litigio constitucional en defensa del agua potable de Lima". $I D L, 31$ de may. de 2019. https://idl.org.pe/litigio-constitucional-en-defensa-del-agua-potable-de-lima/ 
- Instituto Nacional de Estadística e Informática, Perú: Formas de acceso al agua y Saneamiento Básico - Sintesis Estadística, 2016.

https://www.inei.gob.pe/media/MenuRecursivo/boletines/boletin_agua.pdf

- Jara, Fernanda. "El \#10YearChallenge más triste: las especies animales que se extinguieron en la última década". Infobae, 19 de ene. de 2019.

https://www.infobae.com/sociedad/2019/01/19/el-10yearchallenge-mas-triste-las-especiesanimales-extintas-en-la-ultima-decada/

- Llacsahuanga, Richard y Juan Carlos Díaz Colchado, Mesa Temática N²: El derecho fundamental al agua. Presentación, 09 de oct. de 2017. http://themis.pe/wp-content/uploads/2017/09/Mesa-2.docx

- Martínez, Esperanza y Alberto Acosta. "Los Derechos de la Naturaleza como puerta de entrada a otro mundo posible”. Direito e Práxis, 4, vol. 8 (2017): 2927-2961. https://doi.org/10.1590/2179-8966/2017/31220

- Molina, Aurora. "Nuevo constitucionalismo en América Latina. Contexto sociopolítico, derechos sociales. Entrevista a Carlos Rivera Lugo". Crítica Jurídica, 35 (2013): 315-330. http://www.revistas.unam.mx/index.php/rcj/article/view/40811

- Organización de las Naciones Unidas, Comité sobre los Derechos Económicos, Sociales y Culturales. Observación General Nº. 15, acceso 10 de diciembre de 2019, https://www.acnur.org/fileadmin/Documentos/BDL/2012/8789.pdf

- Organización Mundial de la Salud. "El Derecho al agua”. Folleto Informativo No 35, 2011. https://www.ohchr.org/Documents/Publications/FactSheet35sp.pdf

- Naranjo, Mónica. "Derechos de la Naturaleza y la Gestión de la Defensoría del Pueblo de Ecuador". Tesis de Maestría. FLACSO, 2016.

- Pari-Bedoya, Ilda. "Notas sobre el 'buen vivir' y el 'Nuevo Constitucionalismo Latinoamericano"'. Pacarina del Sur, 38, año 10 (2019). www.pacarinadelsur.com/index.php?option=com_content\&view=article\&id=1703\&catid=3

- Ramírez, Pablo. La Naturaleza como Sujeto de Derechos: Materialización de los Derechos, Mecanismos Procesales y la Incidencia Social en el Ecuador. Quito: FLACSO, 2012.

- Ríos, Lautaro. "La Soberanía, el Poder Constituyente y una nueva constitución para Chile". Estudios Constitucionales, 2, año 15 (2017): 167- 202. https://doi.org/10.4067/S0718-52002017000200167 
- Rodríguez, Ignacio. "La tesis de los límites físicos del crecimiento: una revisión de los informes del Club de Roma”. Perspectivas, 2, vol. 5 (2011): 75-103.

- Rosillo, Alejandro. "Pluralismo Jurídico en el constitucionalismo mexicano frente al nuevo Constitucionalismo Latinoamericano”. Revista Direito e Práxis, 4, vol.8 (2017): 3037-3068. https://doi.org/10.1590/2179-8966/2017/31224

- Salazar, Elizabeth. "Mineras extraen agua de zonas en riesgo de sequía”. Portal Ojo Público, 02 de feb. de 2018. https://duenosdelagua.ojopublico.com/especiales/mapadelagua/

- Salazar, Pedro. "El Nuevo Constitucionalismo Latinoamericano (una perspectiva crítica)". En: El constitucionalismo contemporáneo. Homenaje a Jorge Carpizo, ed. L. González-Pérez y D. Valadés, 345-387, México: Universidad Autónoma de México, 2013. https://archivos.juridicas.unam.mx/www/bjv/libros/7/3271/22.pdf

- Salazar, Víctor y Juan Lariz. "A herencia de la visión antropocéntrica y su origen histórico, obstáculo para el desarrollo sustentable”. 20 Encuentro Nacional sobre Desarrollo Regional en México. Cuernavaca, Morelos del 17 al 20 de noviembre de 2015. https://docplayer.es/90351314-La-herencia-de-la-vision-antropocentrica-y-su-origen-historicoobstaculo-para-el-desarrollo-sustentable.html

- Soriano B. Derechos de la naturaleza; las nociones del antropocentrismo y biocentrismo en las constituciones de México y Ecuador. México: Universidad Autónoma de Baja California Sur, 2018, 57.

- $\quad$ Soriano, C, Jacobo, Y. y Núñez, J. "El Reconocimiento Constitucional del Derecho al Agua en el Salvador”. Tesis de grado. Universidad de el Salvador, 2012.

- Sotillo, Aquiles. "La nueva clasificación de los derechos fundamentales en el nuevo constitucionalismo latinoamericano". Revista Ciencia y Cultura, 35, vol. 19 (2015): 163-183.

- The Carter Center. Informe sobre la Asamblea Constituyente de la República del Ecuador. Quito: Centro Carter.

https://www.cartercenter.org/resources/pdfs/peace/americas/Informe_Final_AC_-_Centro_ Carter_distribuido.pdf

- Tórtora, Hugo. "Los derechos sociales en el nuevo constitucionalismo latinoamericano". Revista de Derechos Fundamentales, 13 (2015): 109-133.

- Vacaflores, Carlos. "La economía plural en Bolivia”. Apuntes, 3 (2017): 1-22.

- Velázquez, José Manuel. “Constitucionalismo verde en Ecuador: Derechos de la Madre Tierra y Buen Vivir”. Entramado, 1, vol.10 (2014): 220-238. 
- Ríos, Lautaro. "La Soberanía, el Poder Constituyente y una nueva constitución para Chile". Estudios Constitucionales, 2, año 15 (2017): 167- 202. https://doi.org/10.4067/S0718-52002017000200167

- Rodríguez, Ignacio. "La tesis de los límites físicos del crecimiento: una revisión de los informes del Club de Roma”. Perspectivas, 2, vol. 5 (2011): 75-103.

- Rosillo, Alejandro. "Pluralismo Jurídico en el constitucionalismo mexicano frente al nuevo Constitucionalismo Latinoamericano”. Revista Direito e Práxis, 4, vol.8 (2017): 3037-3068 https://doi.org/10.1590/2179-8966/2017/31224

RECIBIDO: $11 / 09 / 2020$

APROBADO: $28 / 10 / 2020$ 